University of Wollongong

Research Online

Faculty of Engineering and Information

Faculty of Engineering and Information

Sciences - Papers: Part B

Sciences

2018

\title{
Mathematical modelling of the removal of organic micropollutants in the activated sludge process: a linear biodegradation model
}

Mark Nelson

University of Wollongong, mnelson@uow.edu.au

Rubayyi T. Alqahtani

Al Imam Muhammad Ibn Saud Islamic University

Faisal I. Hai

University of Wollongong, faisal@uow.edu.au

Follow this and additional works at: https://ro.uow.edu.au/eispapers1

Part of the Engineering Commons, and the Science and Technology Studies Commons

Research Online is the open access institutional repository for the University of Wollongong. For further information contact the UOW Library: research-pubs@uow.edu.au 


\title{
Mathematical modelling of the removal of organic micropollutants in the activated sludge process: a linear biodegradation model
}

\author{
Abstract \\ Before wastewaters can be released into the environment, they must be treated to reduce the \\ concentration of organic pollutants in the effluent stream. There is a growing concern as to whether \\ wastewater treatment plants are able to effectively reduce the concentration of micropollutants that are \\ also contained in their influent streams. We investigate the removal of micropollutants in treatment plants \\ by analysing a model that includes biodegradation and sorption as the main mechanisms of \\ micropollutant removal. For the latter a linear adsorption model is used in which adsorption only occurs \\ onto particulates. The steady-state solutions of the model are found and their stability is determined as a \\ function of the residence time. In the limit of infinite residence time, we show that the removal of \\ biodegradable micropollutants is independent of the processes of adsorption and desorption. The \\ limiting concentration can be decreased by increasing the concentration of growth-related \\ macropollutants. Although, in principle, it is possible that the concentration of micropollutants is \\ minimized at a finite value of the residence time, this was found not to be the case for the particular \\ biodegradable micropollutants considered.For nonbiodegradable pollutants, we show that their removal is \\ always optimized at a finite value of the residence time. For finite values of the residence time, we obtain \\ a simple condition which identifies whether biodegradation is more or less efficient than adsorption as a \\ removal mechanism. Surprisingly, we find that, for the micropollutants considered, adsorption is always \\ more important than biodegradation, even when the micropollutant is classified as being highly \\ biodegradable with low adsorption. \\ Disciplines \\ Engineering | Science and Technology Studies

\section{Publication Details} \\ Nelson, M. I., Alqahtani, R. T. \& Hai, F. I. (2018). Mathematical modelling of the removal of organic \\ micropollutants in the activated sludge process: a linear biodegradation model. Australia and New \\ Zealand Industrial and Applied Mathematics (ANZIAM) Journal, 60 (2), 191-229.
}




\title{
Mathematical modelling of the removal of
}

\section{organic micropollutants in the activated sludge process: Linear biodegradation model}

\author{
Mark I. Nelson ${ }^{\mathrm{a}}$, Rubayyi T. Alqahtani ${ }^{\mathrm{b}}$, Faisal I. Hai ${ }^{\mathrm{c}}$ \\ June 7, 2018
}

${ }^{a}$ School of Mathematics and Applied Statistics, University of Wollongong, NSW 2522, AusTRALIA.

b Department of Mathematics and Statistics, College of Science, Al-Imam University, Riyadh: 11566, Saudi Arabia.

${ }^{\mathrm{c}}$ Strategic Water Infrastructure Laboratory, School of Civil, Mining and Environmental Engineering, University of University, NSW 2522, Australia.

\begin{abstract}
Before wastewaters can be released into the environment, they must be treated to reduce the concentration of organic pollutants in the effluent stream. There is growing concern as to whether wastewater treatment plants are able to effectively reduce the concentration of micropollutants that are also contained in their influent streams. We investigate the removal of micropollutants in treatment plants by analysing a model that includes biodegradation and sorption as the main mechanisms of micropollutant removal. For the latter a linear adsorption model is used in which adsorption only occurs onto particulates.

The steady-state solutions of the model were found and their stability determined as a function of the residence time. In the limit of infinite residence time we showed that the removal of biodegradable micropollutants is independent of the processes of adsorption and desorption. The limiting concentration can be decreased by increasing
\end{abstract}


the concentration of growth-related macropollutants. Although, in principle, it is possible that the concentration of micropollutants is minimised at a finite value of the residence time, this was found not to be the case for the particular biodegradable micropollutants considered.

For non-biodegradable pollutants we showed that their removal is always optimised at a finite value of the residence time.

For finite values of the residence time we obtained a simple condition which identifies whether biodegradation is more or less efficient than adsorption as a removal mechanism. Surprisingly we found that, for the micropollutants considered, adsorption is always more important than biodegradation, even when the micropollutant is classified as being highly biodegradable with low adsorption.

Keywords: activated sludge; biodegradation; mathematical modelling; micropollutants; wastewater treatment.

\section{Introduction}

Conventional wastewater treatment plants (WWTPs) can effectively remove bulk carbonaceous organic materials as well as nutrients such as nitrogen and phosphorus. However they were not designed to remove organic micropollutants which are detected in trace concentrations, i.e. micropollutants, [1]. Common micropollutants include chemicals associated with personal care products, such as pharmaceutical compounds and their derivatives, and chemicals associated with domestic use, such as pesticides and surfactants. Other common micropollutants include hormones, metals and polycyclic aromatic hydrocarbons (PAH). The release of micropollutants into aquatic ecosystems has been shown to have an ecotoxic impact. This has lead to European legislation mandating both industry and states to reduce their release [2].

The introduction of relevant legislation has spurred experimental investigations into the removal mechanisms of typical micropollutants. The development of well-analysed mathematical models can provide a tool for decision-makers to evaluate the relative importance of the mechanisms which remove micropollutants. These models can also be used to optimise the operation of wastewater treatment plants to significantly reduce the micropollutant concentration downstream of a WWTP. This optimisation must be achieved without adversely effecting the 
removal of 'standard' organic pollutants. A literature review outlining current knowledge about the threats posed by micropollutants, detailing current mathematical models is presented in section 1.1 .

We formulate a mathematical model for the removal of organic micropollutants from municipal wastewaters. The model includes the four main mechanisms leading to micropollutant removal: biodegradation, cometabolism, volatilisation and sorption [3]. In this paper we investigate the special case in which the only removal mechanisms are biodegradation and sorption. Identifying the relative importance of each of these mechanisms is a major challenge for emerging new micropollutants. A surprising finding from our model is that, for the nine biodegradable micropollutants considered, adsorption is always a more important removal mechanism than biodegradation — even for four micropollutants that have been identified as being "highly biodegradable with low sorption".

\section{$1.1 \quad$ Literature Review}

Mathematical models for the removal of micropollutants in WWTPs have recently been reviewed by Pomiès et al [3]. These authors found 18 models published over the period 19892010.

There are four main mechanisms by which micropollutants are removed in WWTPs [3]. These are biodegradation, cometabolism, mass transfer into the gas-phase and sorption onto particulates. These mechanisms do not necessarily apply to all contaminants. For example, only volatile organic compounds are removed by mass transfer into the gas-phase. Additional mechanisms may apply to some contaminants. For example, heavy metals can be removed by precipitation. Identifying the most important removal mechanism for a particular contaminant is one of the applications of mathematical models.

Table 1 summarises the removal mechanisms that have been included in models. All models, excepting those for heavy metals, include biotransformation and sorption-desorption processes. In sections 1.1.1-1.1.3 we review the modelling of biodegradation and cometabolism, the processes of adsorption and desorption, and mass transfer, respectively. In section 1.1.4 we provide a limited review of activated sludge process (ASP) models, restricting our attention to those models that have been used within the context of modelling the removal of micropollutants. 


\begin{tabular}{|l|c|c|c|c|c|c|c|}
\hline \multicolumn{1}{|c|}{ Author } & \multicolumn{2}{|c|}{ Biological conversion } & & & & \multirow{2}{*}{} \\
& $\mathrm{AP}$ & $\mathrm{PP}$ & $\mathrm{DCM}$ & $\mathrm{AD}$ & $\mathrm{DES}$ & $\mathrm{MT}$ & Precipitation \\
\hline Abegglen et al [4] & $\mathrm{X}$ & - & - & $\mathrm{X}$ & $\mathrm{X}$ & - & - \\
Delgadillo-Mirquez et al $[5]$ & $\mathrm{X}$ & $\mathrm{X}$ & $\mathrm{X}$ & $\mathrm{X}$ & $\mathrm{X}$ & $\mathrm{X}$ & - \\
Fernandez-Fontaina et al [6] & $\mathrm{X}$ & - & - & $\mathrm{X}$ & $\mathrm{X}$ & - & - \\
Fernandez-Fontaina et al [7] & $\mathrm{X}$ & - & - & $\mathrm{X}$ & $\mathrm{X}$ & $\mathrm{X}$ & - \\
Jacobsen and Arvin [8] & $\mathrm{X}$ & - & - & $\mathrm{X}$ & $\mathrm{X}$ & - & - \\
Joss et al $[9]$ & $\mathrm{X}$ & - & - & $\mathrm{X}$ & $\mathrm{X}$ & - & - \\
Melcer et al $[10]$ & $\mathrm{X}$ & - & - & $\mathrm{X}(*)$ & $\mathrm{X}(*)$ & $\mathrm{X}$ & - \\
Parker et al [11] & - & - & - & $\mathrm{X}(*)$ & $\mathrm{X}(*)$ & - & $\mathrm{X}$ \\
Siegrist et al [12] & $\mathrm{X}(\mathrm{S})$ & - & - & $\mathrm{X}$ & $\mathrm{X}$ & - & - \\
Urase and Kikuta [13] & $\mathrm{X}$ & - & - & $\mathrm{X}$ & $\mathrm{X}$ & - & - \\
\hline
\end{tabular}

Table 1: Micropollutant removal mechanisms included in activated sludge process models. AD: Adsorption. AP: Aqueous biodegradation. PP: Particulate biodegradation. DCM: biodegradation on dissolved and colloidal matter. DES: Desorption. MT: mass transfer. (S): Removal of the micropollutant is associated with the growth of a specialised biomass, i.e. it is considered as a growth substrate for this species. (*) Assumes that the desorption-sorption process is at equilibrium.

\subsubsection{Modelling the biological removal of micropollutants through biodegradation and cometabolism}

Micropollutants may be removed from WWTPs through the action of biomass. This may be referred to either as the biological conversion of micropollutants or the biotransformation of micropollutants. Two process by which this transformation can occur are biodegradation and cometabolism. There is no standard definition of what 'biodegradation' means in the context of the removal of micropollutants [3]. A common interpretation is that it is the removal of micropollutants in a process which is not associated with the growth of the microorganism. Furthermore, it is widely assumed, as shown in table 1, that biodegradation only happens in the aqueous phase. This assumption has been investigated by Delgadillo-Mirquez et al [5].

Cometabolism refers to micropollutant degradation in the presence of another easily degradable substrate. In this case the micropollutants do not serve as the source of carbon for microbial growth. [14]. Many organic micropollutants present in wastewater treatment plants are biodegraded by a cometabolic mechanism.

The total rate of biological removal $\left(r_{\text {bio }},\left[\mu \mathrm{g} \mathrm{L}^{-1}\right.\right.$ day $\left.\left.{ }^{-1}\right]\right)$ is given by the sum of the rate of cometabolism and the rate of biodegradation

$$
r_{\text {bio }}=T_{C} \frac{\mu\left(S_{S}\right)}{Y_{H}} \cdot\left(\frac{C_{S}}{K_{S C}+C_{S}}\right) X+k_{c} \cdot\left(\frac{C_{S}}{K_{S C}+C_{S}}\right) X
$$


where the first and last terms on the RHS of equation (1) are the rate due to cometabolism and the rate due to biodegradation, respectively. In equation (1) $C_{s}$ is the concentration of soluble micropollutants $\left[\mu \mathrm{g} \mathrm{L}^{-1}\right]$ and $X$ is the concentration of active biomass $\left[\mathrm{g} \mathrm{COD} \mathrm{L}^{-1}\right]$. The specific growth rate, $\mu(S)\left[\right.$ day $\left.^{-1}\right]$, of the biomass upon the soluble substrate, $S_{S}$ [g COD L $\left.{ }^{-1}\right]$, is given by a Monod model

$$
\mu=\mu_{\max } \cdot \frac{S_{S}}{K_{S}+S_{S}}
$$

The remaining constants in equations (1) and (2) are: $K_{S}\left[\left(\mathrm{~g} \mathrm{COD} \mathrm{L}^{-1}\right)\right]$, the Monod halfsaturation constant for the growth of heterotrophic biomass; $K_{S C}$ the half-saturation constant of micropollutants; $T_{C}$ the micropollutant transformation capacity; which represents $Y_{H}$ $\left[\left(\mathrm{g} \mathrm{COD} \mathrm{L}^{-1}\right) /\left(\mathrm{g} \mathrm{COD} \mathrm{L}^{-1}\right)\right]$, the growth yield; $k_{c}\left[\left(\mu \mathrm{g}(\mathrm{g} \text { COD day })^{-1}\right)\right]$, the maximum rate of biodegradation of the micropollutant; and $\mu_{\max }\left[\right.$ day $\left.^{-1}\right]$, the maximum growth rate of the biomass.

Equation 1 is often simplified by putting the micropollutant transformation capacity equal to zero $\left(T_{c}=0\right)$. This removes the cometabolism term, giving

$$
r_{\text {biol }}\left(T_{C}=0\right)=k_{c} \cdot \frac{C_{S}}{K_{S C}+C_{S}} X
$$

This formulation implies that biological conversion of the micropollutant is not associated with growth of the biomass.

The rate functions given in equations (1) and (3) may be further modified by multiplying them by switching functions which have the effect of turning biodegradation 'off' if the concentration of a particular substance is either too 'high' (inhibition) or too 'low'. The use of switching functions to modify growth rates is described in [15].

Micropollutants are generally present at low concentrations in WWTPs. Consequently the rate of biodegradation may be simplified to

$$
r_{\text {biol }}\left(T_{C}=0, C_{S} \ll K_{S C}\right)=k_{\text {biol }} C_{S} X,
$$

where $k_{\text {biol }}=k_{c} / K_{S C}\left[\mathrm{~L}(\mathrm{~g} \text { COD day })^{-1}\right]$, is the degradation rate coefficient. (Formally this requires $\left.C_{S} \ll K_{S C}\right)$. Under circumstances in which the biomass concentration is constant 
equation (4) reduces to the first-order rate law

$$
r_{\text {biol }}\left(T_{C}=0, C_{S} \ll K_{S C}, X=\text { constant }\right)=k_{\text {biol }}^{\prime} C_{S},
$$

where $k_{\mathrm{biol}}^{\prime}=k_{\mathrm{biol}} X\left[\right.$ day $\left.^{-1}\right]$, is the degradation rate coefficient. This rate expression has been widely used to model the environmental removal of organic pollutants.

Regardless of the model used, it is widely assumed that the micropollutant do not provide a food source for active biomass. This assumption is justified as the micropollutant is only present in trace levels, typically $\mu \mathrm{gL}^{-1}$, or to be more precise when the concentration of the micropollutants is much smaller than the concentration of the soluble substrate.

The use of the rate expressions (1) and (3)-(5) in dynamic models for the biodegradation of micropollutants is summarised in table 2 .

\begin{tabular}{|c|c|c|c|c|}
\hline Author & $\begin{array}{c}\text { Cometabolic Monod, } \\
\text { Eq (1) }\end{array}$ & $\begin{array}{c}\text { Monod, } \\
\text { Eq (3) }\end{array}$ & $\begin{array}{c}\text { Second-order, } \\
\text { Eq (4) }\end{array}$ & $\begin{array}{c}\text { First-order, } \\
\text { Eq (5) }\end{array}$ \\
\hline Abegglen et al $[4]$ & - & - & $\mathrm{X}$ & - \\
Delgadillo-Mirquez et al $[5]$ & $\mathrm{X}$ & $\mathrm{X}$ & - & - \\
Fernandez-Fontaina et al [6] & - & - & - & $\mathrm{X}$ \\
Fernandez-Fontaina et al [7] & $\mathrm{X}$ & - & - & $\mathrm{X}$ \\
Jacobsen and Arvin [8] & - & $\mathrm{X}$ & - & - \\
Joss et al $[9]$ & - & - & $\mathrm{X}$ & - \\
Melcer et al [10] & - & - & $\mathrm{X}$ & - \\
Siegrist et al $[12]$ & - & - & - & - \\
Urase and Kikuta [13] & - & - & - & $\mathrm{X}$ \\
\hline
\end{tabular}

Table 2: The biotransformation model used to model the biodegradation of a micropollutant.

\subsubsection{Modelling adsorption-desorption}

We now turn our attention to the modelling of adsorption-desorption processes. Despite the possible nonlinear behaviour of adsorption, a linear adsorption model is always chosen due to the assumed low concentration of micropollutants. The standard assumption is that adsorption only occurs onto particulates, i.e. onto a solid phase. However, based upon experimental evidence, Delgadillo-Mirquez et al [5] developed a model in which adsorption can also occur onto dissolved and colloidal matter, i.e. in the aqueous phase. 


\subsubsection{Mass transfer}

Melcer et al [10] modelled volatilisation as being due to two processes: surface volatilisation, which is important for transfer from open tanks such as clarifiers, and air stripping, which occurs in aerated turbulent process vessels. Both processes are modelled by terms of the form

$$
V \frac{\mathrm{d} C_{s}}{\mathrm{~d} t}=-V K_{L a}\left(C_{s}-C_{g}\right)
$$

where $V$ is a suitable volume [L], $t$ is time [day], $K_{L a}$ is a mass transfer coefficient [day ${ }^{-1}$ ], $C_{s}$ is the concentration of soluble micropollutant, and $C_{g}$ is the gaseous concentration of the micropollutant $\left[\mu \mathrm{g} \mathrm{COD} \mathrm{L}^{-1}\right]$. The differences between the two process is in how the mass transfer coefficient is calculated. If it can be assumed that air movement above the clarifier/vessel is sufficient to carry away volatilised compounds then the equilibrium water phase concentration of the volatilised compound is negligible, i.e. $C_{g} \approx 0$.

Delgadillo-Mirquez et al [5] modelled volatilisation as an equilibrium process between soluble and gaseous micropollutants with

$$
V \frac{\mathrm{d} C_{s}}{\mathrm{~d} t}=-V K_{L a}\left(H C_{s}-C_{g}\right)
$$

where $H$ is Henry's constant [-], which describes the equilibrium between gas phase and the soluble concentration of micropollutant.

Fernandez-Fontaina [7] modelled volatilisation by the term

$$
V \frac{\mathrm{d} C_{s}}{\mathrm{~d} t}=-H \cdot Q_{\mathrm{air}} \cdot C_{s}
$$

where $Q_{\text {air }}$ is the aeration flowrate $\left[L_{\text {air }}\right.$ day $\left.^{-1}\right]$. This formulation assumes that air movement above the aerated vessel ensures that the equilibrium gas-phase concentration of the micropollutant is negligible. This is the approach used in this paper.

\subsubsection{Dynamic models}

In a dynamic model a system of differential equations is written down for the removal of the micropollutant. The alternative is a static model, in which steady-state expressions for the state 
variables are developed without starting from a system of differential equations. Such models may assume that adsorption-desorption processes reach an equilibrium on a faster timescale than that of other processes.

Static models include those of Byrns [16], Cowan et al [17], Fernandez-Fontaina et al [18], Struijs et al [19], Suarez et al [20] and Wang et al [21].

Dynamic models involve state variables associated with the operation of the ASP. Which variable are involved depends upon what assumptions are made but they commonly include soluble substrate, total suspended solids and biomass concentration. A key question is therefore how to model the removal of macropollutants in the activated sludge process (ASP)?

The simplest approach is not to model the ASP, but to measure the values of the state variables required for the micropollutant sub-model. The second approach is to use a simplified model for the ASP consisting of a limited number, typically one or two, biochemical processes. The third approach uses a detailed model for the ASP, such as the activated sludge model number 1 (ASM1) [15] which has been developed to simulate the removal of nutrients and organic matter in WWTPs. A final approach is to use a 'black box' model to simulate the ASP.

In sections 1.1.4.1-1.1.4.4 we overview how the ASP has been modelled within the context of models for the removal of micropollutants. This is not a literature review of ASP models.

\subsubsection{No ASP model (experimental measurements) Micropollutant removal from} a batch reactor has been modelled by Abegglen et al [4], Fernandez-Fontaina et al [6] and Urase and Kikuta [13]. (Fernandez-Fontaina et al [6] also investigated removal in a membrane bioreactor). In [4] and [13] the required inputs were the mixed liquor suspended solids concentration and the total suspended solids, respectively. In [6] the required inputs were the biomass concentration and the total solids concentration.

Fernandez-Fontaina et al [7] developed a model for micropollutant removal based upon cometabolic kinetics by nitrifying biomass. The first-order kinetic model (5) was used. The required experimental inputs are the concentrations of biomass, growth substrate and total suspended solids. These models were used to analyse the removal of twelve micropollutants associated with pharmaceutical use. Four of these compounds were found not to be biodegradable. The biotransformation of four of the compounds was found to be more accurately predicted by cometabolic Monod-type kinetics. 
1.1.4.2 Simplified model for the ASP The ASP model used by Joss et al [9] contains a single-step biochemical model. This step is the growth of active biomass by consumption of soluble substrate. Their model was used to investigate the impact of the reactor configuration upon the removal of the micropollutant. It was found that the use of a reactor cascade appreciably improved the removal of non-sorbing and biodegradable micropollutants compared to a single reactor.

The ASP model used by Jacobsen and Arvin [8] and Delgadillo-Mirquez et al [5] contains a two-step biochemical model. The first step is the hydrolysis of slowly biodegradable particulate substrate to produce soluble substrate. The second step is biodegradation of the soluble substrate through biomass growth. A third process is biomass decay. The model of Jacobsen and Arvin [8] can be viewed as a simplification of the ASM1 [15]. This is not the case for the model of Delgadillo-Mirquez et al [5]. For example, the models differ in how hydrolysis is modelled. The former models hydrolysis using Contois kinetics whereas in the latter it is described as a first-order process (with respect to the particulate concentration).

A non-standard assumption made by Jacobsen and Arvin [8] is that the micropollutant is biodegraded not by the 'regular' biomass but by a specialised microbial species. The micropollutant subsystem consists of five process: growth of the specialised biomass by consumption of soluble substrate, biodegradation of the micropollutant by the specialist biomass, decay of the specialised biomass and adsorption and desorption processes associated with the micropollutant. It is assumed that growth of the specialised biomass upon the micropollutant is negligible.

The incorporation of a specialist biomass represents the addition of a specific microbial culture to the ASP with the hope that it will better remove the micropollutant than the 'standard' WWTP biomass. This strategy is known as biosupplementation or bioaugmentation.

Delgadillo-Mirquez et al [5] developed a micropollutant submodel in which the micropollutant can adsorb onto a solid phase, i.e. onto particulates, and into the liquid phase, i.e. onto dissolved and colloidal matter (DCM). In addition to biodegradation of the soluble micropollutant, the adsorbed micropollutant, both that adsorbed onto DCM and that adsorbed onto the particulates, may be biodegraded. As the rate of biodegradation in the DCM component is different from that for the soluble micropollutant, indeed it may be zero, the existence of this 
component can influence the distribution and bioavailability of the micropollutant.

The model was used to investigate two hypotheses. The first compared the use of a cometabolic model for biodegradation against the use of a pure Monod model; the former provided a better fit to experimental data. The second hypothesis tested which compartment is available for biodegradation. The best fit to experimental data was obtained when it was assumed that only soluble micropollutant is available for biodegradation.

\subsubsection{A detailed model for the ASP Siegrist et al [12] model the ASP using the ASM1} model. A non-standard assumption is made that the micropollutant (nitrilotriacetate, NTA) is biodegraded not by the 'regular' biomass but by a specialised microbial species. Unlike the model developed by Delgadillo-Mirquez et al [5], discussed in section 1.1.4.2, which made the same non-standard assumption, the specialised biomass grows through consumption of both soluble substrate and the micropollutant. Thus the micropollutant acts as a growth substrate and its removal is associated with the growth of the microorganism, i.e. it is not 'biodegraded' in the same sense as in the other models discussed in this review.

The micropollutant submodel contains five processes. There are two processes describing the growth of the specialised biomass, the decay of the specialised biomass and the reversible adsorption of the micropollutant onto suspended solids. Associated with these additional process are three additional state variables: soluble NTA $\left(S_{\mathrm{NTA}}\right)$, the biomass of NTA degraders $\left(X_{\mathrm{B}, \mathrm{NTA}}\right)$ and adsorbed NTA $\left(X_{\mathrm{NTA}}\right)$.

The five process model was too complex to be fitted against experimental data. A simplified scheme, in which two processes were removed, could be fit against the available data. The removed processes were the growth of NTA degraders upon soluble substrate and decay of the NTA degraders.

1.1.4.4 A 'black box' approach to modelling the ASP Melcer et al [10] and Parker et al [11] developed models to simulates the operation of activated sludge systems using the TOXCHEM computer package. TOXCHEM describes contaminant removal in the grit chamber, the primary clarifier, the aeration basin and the secondary clarifier.

Melcer et al [10] developed a model that applies to WWTPs using either diffused or surface aeration. An interesting feature of this model is that mass transfer into the gas phase is 
modelled through two mechanisms: surface volatilization and air stripping. It is assumed that sorption and desorption are at equilibrium.

The model developed by Parker et al [11] simulates the removal of metals. Consequently, biodegradation and mass transfer mechanisms are eliminated. Metals are removed by sorption onto biological solids and by precipitation.

\section{Biochemical processes}

In this section, we describe the biochemical processes and reactions that are included in the model. There are three biochemical reactions. Two of these, equations (6) and (7), are associated with the activated sludge process. The third reaction, equation (8), is the degradation of the micropollutants by the biomass.

The model includes two physical processes. These are sorption of the micropollutants onto the suspended solids, equation to form particulate micropollutants, (9), and desorption of the particulates, equation (10).

Soluble substrate $\left(S_{s}\right)$ is consumed by the biomass $\left(X_{B, H}\right)$ to produce new biomass

$$
S_{s} \underset{X_{B, H}}{\stackrel{\mu\left(S_{s}\right)}{\longrightarrow}} Y_{H} X_{B, H}
$$

In this equation the parameter $Y_{H}\left[\left(\mathrm{~g} \mathrm{COD} \mathrm{L}^{-1}\right) /\left(\mathrm{g} \mathrm{COD} \mathrm{L}^{-1}\right)\right]$ is the heterotrophic yield coefficient.

Death of particulate biomass

$$
X_{B, H} \stackrel{b_{H}}{\longrightarrow} \text { decay products, }
$$

where $b_{H}\left[\right.$ day $\left.^{-1}\right]$ is the heterotrophic decay coefficient. The decay products formed by the decay of particulate matter are not considered in the model. 
Biological removal of micropollutants

$$
C_{s} \underset{X_{B, H}}{\stackrel{k_{\text {biol }}}{\longrightarrow}} \text { products. }
$$

The products formed during the biological removal of micropollutants are not considered in the model.

Sorption

$$
C_{s}+\operatorname{TSS} \stackrel{k_{\mathrm{sor}}}{\longrightarrow} C_{p}
$$

In this equation TSS $\left[\mathrm{g} \mathrm{SS} \mathrm{L}^{-1}\right]$ represents the total suspended solids whilst $k_{\text {sor }}\left[\mathrm{L}(\mathrm{g} \text { SS day })^{-1}\right]$ is the kinetic constant for adsorption.

Desorption

$$
C_{p} \stackrel{k_{\mathrm{des}}}{\longrightarrow} C_{s}+\mathrm{TSS}
$$

In this equation $k_{\text {des }}\left[\right.$ day $\left.^{-1}\right]$ is the kinetic constant for desorption.

The parameter $K_{d}\left[\mathrm{~L}(\mathrm{~g} \mathrm{SS})^{-1}\right]$ is the equilibrium constant for the sorption-desorption process. By definition

$$
K_{d}=\frac{k_{\mathrm{sor}}}{k_{\mathrm{des}}}
$$

\section{Equations}

In line with practical operation we formulate the model assuming that aeration is tightly controlled so that dissolved oxygen does not limit the growth of biomass; consequently it is not 
needed as a state variable.

\subsection{The dimensional model}

The model contains two differential equations for the activated sludge process, equations (12) and (13), and two equations for the dynamics of the micropollutants, equations (14) and (15).

The rate of change of soluble substrate

$$
V \frac{\mathrm{d} S_{S}}{\mathrm{~d} t}=F\left(S_{s, \text { in }}-S_{S}\right)-\frac{\mu_{\max }}{Y_{H}} \cdot M_{2}\left(S_{S}\right) \cdot X_{B, H} \cdot V
$$

where the parameters $V F, S_{S, \text { in }}$, and $M_{2}$ are the volume of the bioreactor [L] flowrate through the bioreactor $\left[\mathrm{L} \mathrm{day}^{-1}\right]$, the substrate concentration in the feed $\left[\mathrm{g} \mathrm{COD} \mathrm{L}^{-1}\right]$ and Monod kinetics for readily biodegradable substrate $[-]$, respectively.

The rate of change of particulate biomass (heterotrophs)

$$
\begin{aligned}
V \frac{\mathrm{d} X_{B, H}}{\mathrm{~d} t} & =F\left(X_{B, H, \text { in }}-X_{B, H}\right)+R F(\mathcal{C}-1) X_{B, H}+\mu_{\max } \cdot M_{2}\left(S_{S}\right) \cdot X_{B, H} \cdot V \\
& -b_{H} X_{B, H} V
\end{aligned}
$$

where the parameters $X_{B, H \text {,in }}, C$ and $R$ are the concentration of particulate biomass in the feed $\left[\mathrm{g} \mathrm{COD} \mathrm{L}^{-1}\right]$, the recycle concentration factor $[-]$, and the recycle ratio $[-]$, respectively. These last two parameters are described in more detail in section 3.2.

The rate of change of soluble micropollutants

$$
V \frac{\mathrm{d} C_{s}}{\mathrm{~d} t}=F\left(C_{s, \mathrm{in}}-C_{s}\right)-H Q_{\mathrm{air}} C_{s}-V k_{\mathrm{sor}} X_{\mathrm{TSS}} \cdot C_{s}+V \frac{k_{\mathrm{sor}}}{K_{d}} \cdot C_{p}-V r_{\mathrm{biol}},
$$


where the parameters $C_{s, \text { in }}$ and $X_{\text {TSS }}$ are the concentration of soluble micropollutants in the feed $\left[\mu \mathrm{g} \mathrm{L}^{-1}\right]$ and the total suspended solids $\left[\mathrm{g} \mathrm{SS} \mathrm{L}^{-1}\right]$, respectively.

The rate of change of particulates micropollutants

$$
V \frac{\mathrm{d} C_{p}}{\mathrm{~d} t}=F\left(C_{p, \mathrm{in}}-C_{p}\right)+R F(\mathcal{C}-1) C_{p}+V k_{\mathrm{sor}} X_{\mathrm{TSS}} \cdot C_{s}-V \frac{k_{\mathrm{sor}}}{K_{d}} C_{p}
$$

where the parameter $C_{p, \text { in }}\left[\mu \mathrm{g} \mathrm{L}^{-1}\right]$ is the concentration of particulate micropollutants in the feed.

Monod growth kinetics

$$
M_{2}\left(S_{S}\right)=\frac{S_{S}}{K_{S}+S_{S}}
$$

Residence time

$$
\tau=\frac{V}{F}
$$

where the parameter $\tau$ [day] is the residence time.

Biological removal rate ('linear' biodegradation model)

$$
r_{\mathrm{biol}}=k_{\mathrm{biol}} \cdot X_{B, H} \cdot C_{s}
$$

Total suspended solids

$$
X_{\mathrm{TSS}}=c_{2} X_{B, H},
$$


Table 3: Typical parameters values. The parameters in the table are: $C_{S, \text { in }}$, the concentration of soluble micropollutants in the feed; $K_{S}$, the Monod constant for heterotrophic biomass; $S_{s, \text { in }}$, the substrate concentration in the feed; $Y_{H}$, the heterotrophic yield factor; $b_{H}$, the heterotrophic decay coefficient; $c_{2}$, a conversion factor from units of COD to units of TSS for the heterotrophic biomass; and, $\mu_{\max }$, the maximum specific growth rate for biomass.

\begin{tabular}{lccl}
\hline Parameter & Unit & Value & \multicolumn{1}{c}{ Reference } \\
\hline$C_{\mathrm{s}, \text { in }}$ & $\mu \mathrm{g} \mathrm{L}^{-1}$ & 100 & Fernandez-Fontaina et al [7] \\
$K_{S}$ & $\mathrm{~g} \mathrm{COD} \mathrm{L}^{-1}$ & 0.020 & Yoon and Lee $[22]$ \\
$S_{s, \text { in }}$ & $\mathrm{g} \mathrm{COD} \mathrm{L}^{-1}$ & 0.2 & Yoon and Lee [22] \\
$Y_{H}$ & $\left({\mathrm{~g} \mathrm{COD})(\mathrm{g} \mathrm{COD})^{-1}}^{-1}\right.$ & 0.67 & Yoon and Lee [22] \\
$b_{H}$ & day $^{-1}$ & 0.22 & Yoon and Lee [22] \\
$c_{2}$ & ${\mathrm{~g} \mathrm{SS}\left(\mathrm{g} \mathrm{COD}^{-1}\right.}$ & 0.90 & Jeppsson and Diehl [23] \\
$\mu_{\max }$ & day $^{-1}$ & 6.0 & Yoon and Lee [22]
\end{tabular}

where the parameter $c_{2}$ converts units of chemical oxygen demand to units of total suspended solids [(g SS) / (g COD)]. The nomenclature is defined in appendix A. In equations (12)-(15) the parameters that can be most easily manipulated experimentally are the specific aeration flowrate $\left(Q_{\text {air }}\right)$, the concentration of soluble substrate in the feed $\left(S_{s, \text { in }}\right)$, and the residence time $(\tau)$. The last of these is the main experimental control parameter.

The typical parameter values for the activated sludge process are taken from [22]. The typical parameter values for the variables associated with the micropollutants are taken from [7]. These values are presented in tables 3 and 4, respectively. The micropollutants are classified into one of four groups depending upon theirs characteristics [7].

In Fernandez-Fontaina et al [7, table 3] the units of the parameter $k_{\text {biol }}$ are L (g VSS day) ${ }^{-1}$. We therefore required a conversion factor to convert these units to units of $\mathrm{L}$ (g COD day) ${ }^{-1}$. This is given by [24, Chapter 2.2.4.1]

$$
\mathrm{COD}=f_{x} \mathrm{VSS}
$$

where

$$
f_{x}=1.42 \mathrm{~g} \text { cell COD } /(\mathrm{g} \text { VSS })
$$

In the following section, we discuss the settling unit model. 
Table 4: Parameters values for the variables associated with the micropollutants. The average value of the two values reported in [7, table 3] has been taken. The parameters in the table are: $K_{d}$, the solid-liquid partitioning coefficient; $k_{\text {biol }}$, the biotransformation kinetic constant; and $k_{\text {sor }}$, the sorption kinetic constant.

\begin{tabular}{lccc}
\hline Type & $k_{\text {biol }} \mathrm{L}(\mathrm{g} \text { COD day })^{-1}$ & $K_{d} \mathrm{~L}(\mathrm{~g} \mathrm{SS})^{-1}$ & $k_{\text {sor }}(\mathrm{g} \mathrm{SS})^{-1}$ \\
\hline Highly biodegradable with low sorption & $>1.42$ & $<100 \times 10^{-3}$ & \\
Ibuprofen (IBP) & 4.76 & $56.5 \times 10^{-3}$ & 96.0 \\
Naproxen (NPX) & 2.84 & $47.0 \times 10^{-3}$ & 129.5 \\
Erythromycin (ERY) & 2.70 & $59.5 \times 10^{-3}$ & 36.0 \\
Roxithromycin (ROX) & 4.05 & $89.5 \times 10^{-3}$ & 236.5 \\
\hline Highly biodegradable with high sorption & $>1.42$ & $>100 \times 10^{-3}$ & \\
Galaxolide (HHCB) & 38.20 & $2704.5 \times 10^{-3}$ & 3036.5 \\
Tonalide (AHTN) & 21.23 & $2346 \times 10^{-3}$ & 1142.5 \\
\hline Slowly biodegradable & $<1.42$ & & \\
Fluoxetine (FLX) & 1.35 & $902.5 \times 10^{-3}$ & 2074.5 \\
Sulfamethoxazole (SMX) & 0.92 & $48.0 \times 10^{-3}$ & 74.5 \\
Trimethoprim (TMP) & 0.64 & $75.5 \times 10^{-3}$ & 96.5 \\
\hline Non biodegradable & 0 & & \\
Diclofenac (DCF) & 0.00 & $17.5 \times 10^{-3}$ & 43.5 \\
Carbamazepine (CBZ) & 0.00 & $125.5 \times 10^{-3}$ & 122.5 \\
Diazepam (DZP) & 0.00 & & \\
\hline
\end{tabular}

\subsection{The ideal settling unit model}

In this section we provide background information on settling units and our submodel for the settling unit: the ideal settling unit model, also known as the perfect or point settling unit model. The purpose of a settling unit, also known as a clarifier, secondary settling unit, sedimentation basin or solids-liquid separator, is to use the process of sedimentation under gravity to separate suspended solids, the biological sludge mass, from the liquid phase, the treated wastewater. Two important processes occurring within a settling unit are clarification and thickening. Clarification, which occurs in the upper zone of a settling unit, is the removal of finely dispersed solids from the liquid. This produces a low turbidity effluent which is suitable for discharge into aquatic environments. Thickening, which occurs in the lower zone of a settling unit, is the concentration of sludge.

A settling unit has two output streams: the effluent stream, from the clarification zone, and the underflow stream, from the thickening zone. The former contains purified water which is low in suspended solids; ideally free of suspended solids. In our figure this is the 'top' stream with flowrate $(1-w) \mathrm{F}$. The latter contains settled concentrated biomass. This is either recycled back into the reactor, through the recycle stream, or sent for disposal, through the wastage 
stream.

Figure 1 shows the process configuration. The flow rate of the recycle stream from the settling unit, denoted $F_{R}$, is written as $F_{R}=R F$, where the parameter $R$ is the recycle rate. The wastage rate from the settling unit, denoted $F_{W}$, is written as $F_{W}=w F$, where $w$ is the fractional wastage. When a settling unit is deployed we have $R>0$.

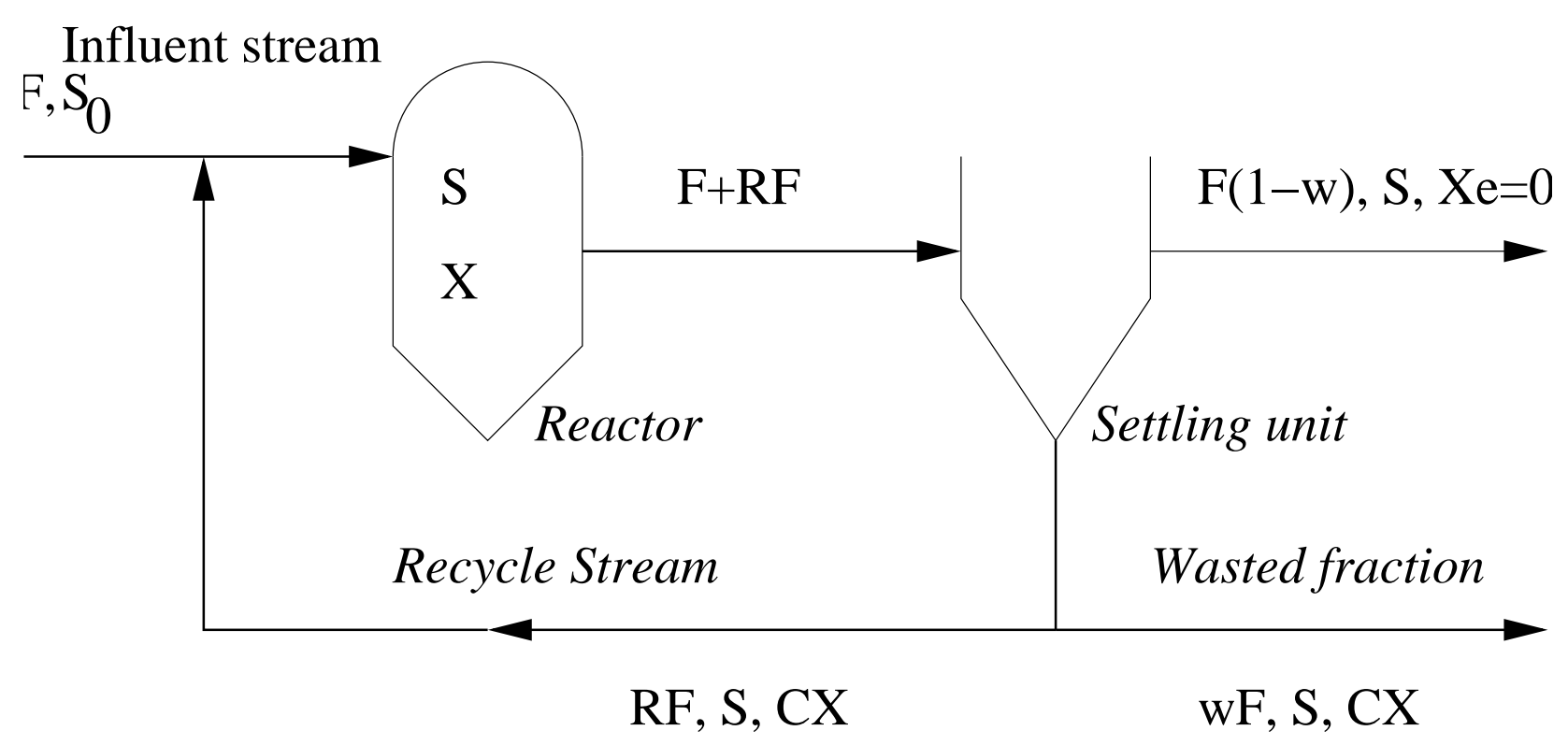

Figure 1: Schematic process configuration illustrating recycle and separate sludge wasting. $C$ is the recycle concentration factor $[(-)] . F$ is the flowrate through the bioreactor $\left[\mathrm{L} \mathrm{day}^{-1}\right] . R$ is the recycle ratio $[(-)] . S$ is the the substrate concentration in the bioreactor $\left[\mathrm{g} \mathrm{COD} \mathrm{L}^{-1}\right] . S_{0}$ is the substrate concentration in the feed $\left[\mathrm{g} \mathrm{COD} \mathrm{L}^{-1}\right] . X$ is the concentration of particulate biomass in the bioreactor $\left[\mathrm{g} \mathrm{COD} \mathrm{L}^{-1}\right] . X_{e}$ is the concentration of particulate biomass in the effluent stream $\left[\mathrm{g} \mathrm{COD} \mathrm{L}^{-1}\right] . w$ is the fraction of the recycle stream that is wasted $[-]$.

The thickening zone concentrates particulates. A common assumption in settling unit models is that all particulates are the same size and are concentrated equally by the settling unit. In the ideal settling unit model the concentration of particulates leaving the settling unit in the underflow is given by $\mathcal{C} P$, where the parameter $\mathcal{C}$ is known as the concentration factor of the settling unit. Note that as the settling unit concentrates particulates we must have $\mathcal{C}>1$. We have $P=X_{B, H}$ in equation (13) and $P=C_{p}$ in equation (15).

A mass balance around the settling unit reveals that the particulate concentration in the effluent stream is

$$
P_{e}=\frac{1-w \mathcal{C}+R(1-\mathcal{C})}{1-w} \cdot P
$$


where $P$ is the concentration in the stream leaving the bioreactor. A standard assumption is that the settling unit captures all particulates. Then $P_{e}=0, \mathcal{C}=\mathcal{C}_{\max }$ and

$$
\left[R\left(\mathcal{C}_{\max }-1\right)\right]=1-w \mathcal{C}_{\max }
$$

This gives the maximum concentration factor as

$$
\mathcal{C}_{\max }=\frac{1+R}{R+w}
$$

The value of $\mathcal{C}_{\max }$ is independent of the process load, only depending upon the recycle ratio $(R)$ and the wastage fraction $(w)$. As $0 \leq w<1$ the value of the maximum concentration factor is guaranteed to be greater than one.

It follows that when all the solids are captured that

$$
R^{*}=R\left[\mathcal{C}_{\max }-1\right]=\frac{R(1-w)}{R+w} .
$$

The parameter grouping $R^{*}=R\left[\mathcal{C}_{\max }-1\right]$ is known as the effective recycle ratio. We have $0 \leq R^{*} \leq 1$. The maximum value $\left(R^{*}=1\right)$ can only be achieved if there is no wastage $(w=0)$. Thus in practice we have $0 \leq R^{*}<1$.

Although highly simplified, the point settler model is considered acceptable for conditions under which the flow rate and the total suspended solids in the influent stream of a WWTP are relatively constant [25]. It is useful when the main focus is on the overall behaviour of the system. Diehl et al note that "It is the most commonly used assumption for steady-state analysis in text books and papers" [26, section 7]. However, when modelling dynamic conditions activated sludge models are mostly coupled with one-dimensional settling unit models [25].

\subsection{Other models for the settling unit}

The ideal settler unit model assumes an highly idealised operation of the settling unit. A key implicit assumption is that the settling unit is able to cope with any flux of particulate matter, 
i.e. all the particulate matter entering the settling unit passes through the thickening zone and leaves in the underflow. However, in practice settling units can not be operated if the flux of particulate matter is over some maximum value; such a situation is known as as overloading. Overloading, which may be due to reasons such as storm weather or settleability deterioration, may lead to process failure, for example particulate matter may be discharged into the effluent stream. The phenomenon of overloading has motivated the design of improved models for settling units. In this section we provide an overview of some relevant work over recent years. Our focus is on models that use solid flux theory. Other approaches are possible, for example by considering the forces acting on settling particles [27].

Takács and Ekama [28] provide an excellent starting point to learn about settling units. They cover settling tank configurations, measures of sludge settleability, and provide an account of flux theory and how it is used to make the engineering calculations that are required for the design and operation of settling units. The section on the modelling of settlers divides post 1990 models into one dimensional (1-D) models and CFD models (2-D or 3-D). The former are more commonly used in conjunction with ASP models whereas the latter are used in the design of settling units.

One-dimensional models describe the vertical sludge profile by discretising the tank into horizontal layers, with uniform concentrations in each layer. This simplifies the hydrodynamic flow within the settling unit to be either 'up', towards the effluent stream, or 'down', towards the underflow. Three major zones are identified: the clarification zone, the inlet zone and the thickening zone. The clarification zone, at the top of the unit, sits above the inlet zone which sits above the thickening zone, at the bottom of the unit. Many assumptions have to be made to reduce the complexity of the model. Standard assumptions include: the constituents of the suspension are incompressible; the stream from the biological reactor is completely flocculated before entering the settling unit; there is no mass transfer between the solid and liquid phases; and that no reactions occur in the settling unit. A fundamental problem in modelling settling units is that the various settling behaviours that can occur are poorly understood [29]. This has led to the wide-spread use of empirical or semi-empirical expressions for terms such as the settling velocity of particulate material.

The most common method describes the settling behaviour of particulates using a single 
concentration variable. Such models can be sub-divided into first-order and second-order models, also referred to as convection and convection-diffusion models, respectively. First-order (convection) models are based upon mass continuity and give raise to a nonlinear hyperbolic PDE. Two mechanisms are used to model the continuity of solids flux: hindered settling due to gravity and bulk transport due to upwards and downwards hydraulic flow. Most early onedimensional models only considered conservation of mass and hindered settling [38, page235].

In second-order (convection-diffusion) models, a diffusion term is included in an attempt to incorporate hydrodynamic features. This gives a nonlinear parabolic PDE. An advantage of second-order models is that there is a clear distinction between settling parameters, which can be measured, and 'lumped parameters', which lump together hydrodynamic effects. which are adjusted during the process of model calibration [25,42].

At low concentrations suspended particles are subject to hindered settling. At high concentrations particles are instead subject to compression settling. This occurs due to the transmission of compressive stress as a consequence of the formation of a (compressible) porous layer of flocculated particles. Although conceptually simple, the constitutive relationships describing compressive behaviour are still unknown [30]. The interface between the region of hindered settling and compression settling is known as the sludge blanket. A major complication in modelling compression is that the location of the sludge blanket is not static. Under conditions of overloading the sludge blanket can move from the 'bottom' of the settling unit to its 'top', resulting in process failure due to the discharge of suspended solids into the effluent stream. The earliest, and simplest, one-dimensional models did not include compressive settling.

The one-dimensional modelling of secondary settling tanks has been reviewed by Li and Stenstrom [29] and by Cadet et al [31]. Li and Stenstrom's review divides into three main parts: settling theory, one-dimensional models, and suitable numerical techniques. In their complementary review, Cadet et al explore the defects in one-dimensional models. These are primarily identified as being a lack of knowledge about the fundamental physical processes occurring within a settling unit and the difficulties in numerically solving the resulting PDE models. A complete CFD simulation of the complicated multiphase fluid motion within a settling tank is currently not feasible due to the wide range of physico-biochemical phenomena occurring inside it and a lack of understanding about the settling characteristics of sludge [32, 
section 6.1].

The most widely used one-dimensional settling tank model in WWTP modelling is the first-order model due to Takács et al [33]. This model has been found to work best with ten layers comprising: the top layer, corresponding to the effluent stream, three clarifier layers, the feed layer, four thickening layers, and the bottom layer, corresponding to the underflow stream. For the applied mathematician a worrying feature of the Takács model is that, as the number of layers is increased, its solution fails to converge to the solution of the underlying PDE [34]. Furthermore, increasing the number of layers deteriorates the fit of the model to experimental data [35]. One reason for such behaviour is that the discretised model includes a parameter, a threshold concentration, which is not present in the PDE model. Despite its defects this model can provide reasonable predictions for settling units running under normal operating conditions, i.e. normal dry weather. It has been "implemented in most commercial simulators as a reference model" [36, page 814]. However, it is not recommended to use it under anomalous operating conditions such as peak flows due to rain [37].

A one-dimensional model that includes compressive settling is the hindered-compressiondispersion model due to Bürger and Diehl, the Bürger-Diehl model. At the time of its publication it was the most advanced one-dimensional settling tank model [36]. The potential advantages of this model include its ability to provide more accurate predictions of underflow concentrations and to determine the location of the sludge blanket under unusual conditions [38].

Torfs et al [37] coupled the Bürger-Diehl settling unit model to the benchmark simulation model no. 1 (BSM1) [39], a standard model for a WWTP. The authors aim was not to investigate a fully calibrated model, rather it was to identify circumstances under which the Bürger-Diehl model captures dynamic features of the settling unit that are not captured by traditional models. The simulations used a standard input file for storm weather conditions.

Li and Stenstrom [36] provide a sensitivity analysis of the Bürger-Diehl model under wetweather flow and sludge bulking conditions. The modelling platform used was the BSM1 [39]. The authors found that the relative importance of the parameters in the settling unit model depended upon the imposed simulation conditions.

Diehl et al [40] investigated the steady-state behaviour of a bioreactor connected to a settling 
unit, the latter using the Bürger-Diehl model. The biological processes were represented by one reaction: the growth of a single biomass species upon one substrate. For their steady-state analysis the authors assume that all the sludge entering the settling unit moves through the thickening zone and that there is no sludge in the effluent stream, i.e. that the settling unit can never be overloaded. To ensure that this was the case the recycle ratio $(R)$ and the wastage ratio $(w)$ unit were varied in order to ensure that the location of the sludge blanket remained level at $1 \mathrm{~m}$.

In Diehl et al [40] the bioreactor was modelled as a continuously stirred tank reactor. In a complementary study the bioreactor was instead assumed to be a plug-flow reactor [26]. As before the authors assume that the reactor can not be overloaded and vary the recycle ratio and the wastage ratio to ensure that the location of the sludge blanket remains fixed at $1 \mathrm{~m}$. One point of difference is that steady-state solutions obtained using the Bürger-Diehl settling tank model are compared those using the ideal settling tank model.

A standard assumption is that no reactions occur in settling units. However, significant denitrification can occur at the bottom of settling tanks. Bürget et al [41] extended the BürgerDiehl model to include biochemical reactions. A kinetic model was used containing five state variables, three soluble species and two particulates. This leads to a system of nonlinear convection-diffusion-reaction PDEs, which had to be solved using a non-standard numerical method. The model was solved within the context of batch settling, it was linked to a model for a WWTP.

A practical obstacle to the use of advanced models for settling units is the paucity of high resolution data sets. Well-collected data sets from batch test are required to calibrate the empirical functions that are ubiquitous in settling unit models. Such tests are labour intensive and typically information poor [38, section 2.2]. Well-collected data sets from WWTPs are required for model validation and comparison. The limited observational data, of both types, has ensured that many settling tank models have not been verified and tested [29]. Even when batch data is available the observational data is limited, meaning that it is difficult to find a unique set of model parameter values. The selection of initial guesses for parameters associated with biomass settleability and compressibility can be challenging due to insufficient knowledge as to what 'typical' values might be [38, section 2.3]. These problems have limited the practical 
applications of advanced settler models, such as the Bürger-Diehl model [36]. The problems associated with parameter identification are exacerbated in advanced settler models due to the additional parameters that they contain compared to traditional models. For example, the Bürger-Diehl model contains additional parameters associated with compressive setting. More recent settling unit models contain close to ten parameters [38, section 4]. Motivated by such concerns the sensitivity of model predictions to both to the choice of settling unit models and the uncertainty in the values of settling unit parameters has been investigated [38, 42].

Ramin et al [42] used global sensitivity techniques to investigate how the choice of settling tank model and the uncertainty in the settling unit model parameters effects the performance of WWTP models. First-order and second-order one-dimensional settling unit models were used. Dynamic simulations were carried out with daily, weekly and seasonal variation in both dry- and wet-weather conditions. The uncertainty in the settling unit parameters were found to be as influential as the uncertainty in the biokinetic parameters of the activated sludge model number 1. Furthermore, the relative importance of the settling unit parameters depended upon which submodel was being considered.

The problem of parameter identifiability in the Bürger-Diehl model without dispersion was considered by Li and Stenstrom [38]. They investigated which settling unit parameters can be identified from which experimental configurations, the influence of the initial guess for the parameter values upon parameter identifiability and how differences in parameter estimates impact the uncertainty in the prediction of a model.

The one-dimensional models discussed above describe the behaviour of the particulates through a single concentration variable. This implies that all the particulates are the same size. Torfs et al [30] have extended the Bürger-Diehl model to include the size-distribution of particles. Not only do the different particle classes have different settleability characteristics but the model contains 'reaction' terms allowing flocculation of smaller particles to produce larger particles and for larger particles to break apart into smaller ones. The model equations were implemented as a batch sedimentation model containing ten particle classes, they were not attached to a WWTP model.

An alternative approach to the use of single-phase models are two-phase models in which both solid and liquid concentrations are modelled. The use of both mass continuity and con- 
servation of momentum leads to a system of four PDEs, two for each phase. Such models provide a more detailed description of physical processes, in particular those associated with the compression zone. However, this greater detail comes at the expense of introducing more processes which must be parameterised and consequently more parameters. Such models have been reviewed by Li and Stenstrom [29].

\section{Biological removal: linear biodegradation model}

\subsection{The dimensionless model}

In this section we study the system (12-15), associated with the linear biotransformation rate defined by equation (18). The model equations (12-15) are scaled using the dimensionless variables: $\left[S^{*}=S_{S} / K_{S}\right],\left[X^{*}=X_{B, H} / Y_{H} K_{S}\right],\left[C_{s}^{*}=C_{s} / C_{s, \mathrm{in}}\right],\left[C_{p}^{*}=C_{p} / C_{s, \text { in }}\right]$ and $\left[t^{*}=\right.$ $\left.\mu_{\text {max }} t\right]$. This process introduces: scaled feed concentrations $\left[C_{p, \text { in }}^{*}=C_{p, \text { in }} / C_{s, \text { in }}, S_{s, \text { in }}^{*}=S_{S, \text { in }} / K_{S}\right.$, $\left.X_{0}^{*}=X_{0} /\left(Y_{K} S_{S}\right)\right]$, a scaled solid-liquid partitioning coefficient $\left[K_{d}^{*}=c_{2} K_{S} Y_{H} \cdot K_{d}\right]$, a scaled specific aeration rate $\left[Q_{\text {eff }}=H Q_{\text {air }} /\left(V \mu_{\max , H}\right)\right]$, an effective recycle ratio $\left[R^{*}=(C-1) R\right]$, a scaled decay rate, $\left[b_{H}^{*}=b_{H} / \mu_{\max , H}\right]$, a scaled biotransformation kinetic constant, $\left[k_{\text {biol }}^{*}=\right.$ $\left.K_{S} Y_{H} \cdot k_{\text {biol }} / \mu_{\max , H}\right]$, a scaled sorption rate, $\left[k_{\mathrm{sor}}^{*}=c_{2} K_{S} Y_{H} \cdot k_{\mathrm{sor}} / \mu_{\max , H}\right]$, and a scaled residence time, $\left[\tau^{*}=\tau \cdot \mu_{\max , H}\right]$. The system of scaled equations is

$$
\begin{aligned}
\frac{d S^{*}}{d t^{*}} & =\frac{S_{s, \text { in }}^{*}-S^{*}}{\tau^{*}}-\frac{X^{*} S^{*}}{1+S^{*}}, \\
\frac{d X^{*}}{d t^{*}} & =\frac{X_{0}^{*}-X^{*}}{\tau^{*}}+\frac{X^{*} S^{*}}{1+S^{*}}-b_{H}^{*} X^{*}+\frac{R^{*} X^{*}}{\tau^{*}}, \\
\frac{d C_{s}^{*}}{d t^{*}} & =\frac{1-C_{s}^{*}}{\tau^{*}}-Q_{\mathrm{eff}} C_{s}^{*}-k_{\mathrm{sor}}^{*} C_{s}^{*} X^{*}+\frac{k_{\mathrm{sor}}^{*}}{K_{d}^{*}} C_{p}^{*}-k_{\mathrm{biol}}^{*} X^{*} C_{s}^{*}, \\
\frac{d C_{p}^{*}}{d t^{*}} & =\frac{C_{p, \text { in }}^{*}-C_{p}^{*}}{\tau^{*}}+\frac{R^{*} C_{p}^{*}}{\tau^{*}}+k_{\mathrm{sor}}^{*} C_{s}^{*} X^{*}-\frac{k_{\mathrm{sor}}^{*}}{K_{d}^{*}} C_{p}^{*} .
\end{aligned}
$$

From now on, we assume that the particulate biomass and the particulate micropollutant concentrations in the feed are zero $\left(X_{0}^{*}=0\right.$ and $\left.C_{p, \text { in }}^{*}=0\right)$. Several authors have reported that stripping, i.e. mass-transfer into the gas phase, is negligible $[4,7,9,13]$. In any case, stripping could only be significant for volatile micropollutants. Urase and Kikuta [13] provide a bound on the value of Henry's constant below which it can be assumed that transfer of compounds to the air phase is negligible. Some models do not contain a mass transfer term as it is assumed 
that biological removal and sorption are much more important that volatilization. Examples of this are models for the removal of pentachlorophenol [8] and nitrilotriacetate [12]. In view of the considerations outlined above we remove the specific aeration term from our model, i.e. $Q_{\text {eff }}=0$.

\subsection{Steady State Solutions}

There are two branches of steady state solutions. The first of these is the washout branch,

$$
\left(S^{*}, X^{*}, C_{s}^{*}, C_{p}^{*}\right)=\left(S_{s, \text { in }}^{*}, 0,1,0\right)
$$

This is so-named because the bioreactor is devoid of biomass $\left(X^{*}=0\right)$. The second of these

istheno - washoutbranch, $\left(S^{*}, X^{*}, C_{s}^{*}, C_{p}^{*}\right)=\left(\widehat{S^{*}}, \frac{S_{s, \mathrm{in}}^{*}-\widehat{S^{*}}}{1-R^{*}+b_{H}^{*} \tau^{*}}, d_{1}\left[1-R^{*}+\tau^{*} \frac{k_{\mathrm{sor}}^{*}}{K_{d}^{*}}\right], d_{1} \tau^{*} k_{\mathrm{sor}}^{*} X^{*}\right)$

$$
\begin{aligned}
\widehat{S^{*}} & =\frac{1-R^{*}+b_{H}^{*} \tau^{*}}{\left(1-b_{H}^{*}\right) \tau^{*}-\left(1-R^{*}\right)}, \\
d_{1} & =\frac{1}{\left[\frac{k_{\mathrm{sor}}^{*}}{K_{d}^{*}} d_{2}+\left(1-R^{*}\right) k_{\mathrm{sor}}^{*} X^{*}\right] \tau^{*}+d_{2}\left(1-R^{*}\right)},
\end{aligned}
$$

$$
d_{2}=1+k_{\mathrm{biol}}^{*} X^{*} \tau^{*}
$$

This is so-named because the bioreactor contains biomass $\left(X^{*}>0\right)$. Note that we have $d_{1}>0$ and $d_{2}>0$.

The no-washout branch is only of interest when the components are positive $\left(0<S_{s}^{*}<S_{s, \text { in }}^{*}\right.$, $\left.X^{*}>0, C_{s}^{*}>0, C_{p}^{*}>0\right)$. These conditions are met if the dimensionless residence time be sufficiently high and the dimensionless decay rate be sufficiently low,

$$
\begin{aligned}
\tau^{*}>\tau_{\mathrm{cr}}^{*} & =\frac{\left(1+S_{s, \text { in }}^{*}\right)\left(1-R^{*}\right)}{S_{s, \text { in }}^{*}-\left(1+S_{s, \text { in }}^{*}\right) b_{H}^{*}}>0, \\
0<b_{H}^{*} & <\frac{S_{s, \text { in }}^{*}}{1+S_{s, \text { in }}^{*}} .
\end{aligned}
$$

(Recall from section 3.2 that we have $0 \leq R^{*} \leq 1$.) 
A transcritical bifurcation occurs when $\tau^{*}=\tau_{\mathrm{cr}}^{*}$. At this point the no-washout and washout solution branches intersect. Note that this critical value approaches zero as the value of the effective recycle parameter approaches its theoretical maximum $\left(R^{*}=1\right)$. The use of a settling unit allows the reactor to operate at lower residence times.

The dimensionless soluble micropollutant concentration and the dimensionless particulate micropollutant concentrations are both decreasing functions of the dimensionless biotransformation kinetic constant $\left(k_{\text {biol }}^{*}\right)$. Differentiating the steady state equations $(25)$ and (26) with respect to $k_{\text {biol }}^{*}$, we obtain

$$
\begin{aligned}
\frac{\mathrm{d} C_{p}^{*}}{\mathrm{~d} k_{\mathrm{biol}}^{*}} & =\frac{-k_{\mathrm{sor}}^{*} X^{* 2} \tau^{* 2} C_{s}^{*}}{\left[X^{*} \tau^{*}\left(k_{\mathrm{sor}}^{*}+k_{\mathrm{biol}}^{*}\right)+1\right]\left[1-R^{*}\right] K_{d}^{*}+k_{\mathrm{sor}}^{*} \tau^{*}\left[k_{\mathrm{biol}}^{*} X^{*} \tau^{*}+1\right]}<0, \\
\frac{\mathrm{d} C_{s}^{*}}{\mathrm{~d} k_{\mathrm{biol}}^{*}} & =\frac{-X^{*} C_{s}^{*} \tau^{*}\left[\left(1-R^{*}\right) K_{d}^{*}+k_{\mathrm{sor}}^{*} \tau^{*}\right]}{\left[X^{*} \tau^{*}\left(k_{\mathrm{sor}}^{*}+k_{\mathrm{biol}}^{*}\right)+1\right]\left[1-R^{*}\right] K_{d}^{*}+k_{\mathrm{sor}}^{*} \tau^{*}\left[k_{\mathrm{biol}}^{*} X^{*} \tau^{*}+1\right]}<0 .
\end{aligned}
$$

(Prior to differentiating equations (25) and (26) it is useful to note that the steady-state expressions for the substrate and biomass concentrations, $S^{*}$ and $X^{*}$, respectively, are independent of the parameter $k_{\mathrm{biol}}^{*}$.) Hence, these concentrations decrease as the dimensionless biotransformation kinetic constant increases. As the value of the dimensionless biotransformation kinetic constant $\left(k_{\text {biol }}^{*}\right)$ increases, the dimensionless soluble micropollutant is more rapidly removed by the biomass. The removal of soluble micropollutant induces more particulate micropollutant to be desorbed.

The soluble micropollutant concentration and the particulate micropollutant concentration are decreasing and increasing as functions of the dimensionless solid-liquid partitioning coefficient $\left(K_{d}^{*}\right)$, respectively. Differentiating the steady state equations (25) and (26) with respect to $K_{d}^{*}$, we obtain

$$
\begin{aligned}
\frac{\mathrm{d} C_{p}^{*}}{\mathrm{~d} K_{d}^{*}} & =\frac{\left(k_{\text {sor }}^{*} \tau^{*}\right)^{2} X^{*} d_{2}}{\left\{\left(1-R^{*}\right) K_{d}^{*} X^{*} k_{\mathrm{sor}}^{*} \tau^{*}+d_{2}\left[k_{\mathrm{sor}}^{*} \tau^{*}+\left(1-R^{*}\right) K_{d}^{*}\right]\right\}^{2}} \\
\frac{\mathrm{d} C_{s}^{*}}{\mathrm{~d} K_{d}^{*}} & =\frac{-\left(1-R^{*}\right)\left(k_{\mathrm{sor}}^{*} \tau^{*}\right)^{2} X^{*}}{\left\{\left(1-R^{*}\right) K_{d}^{*} X^{*} k_{\mathrm{sor}}^{*} \tau^{*}+d_{2}\left[k_{\mathrm{sor}}^{*} \tau^{*}+\left(1-R^{*}\right) K_{d}^{*}\right]\right\}^{2}}
\end{aligned}
$$

(Before carrying out the implicit differentiation it should be noted that the steady-state expressions for the substrate and biomass concentrations are independent of the parameter $K_{d}^{*}$.) In our model formulation increasing the dimensionless solid-liquid partitioning coefficient corre- 
sponds to decreasing the rate of the desorption. It is therefore to be expected that this acts to increase the particulate micropollutant concentration at the expense of the soluble micropollutant concentration. We conclude that the soluble micropollutants concentrations is minimized by taking high values for $k_{\text {biol }}^{*}$ and $K_{d}^{*}$.

\subsection{Local stability}

The local stability of the steady-state solutions is governed by the eigenvalues of the Jacobian matrix of the model (23)-(26). We have

$\mathrm{J}\left(S^{*}, X^{*}, C_{s}^{*}, C_{p}^{*}\right)=\left[\begin{array}{cccc}-A_{1} & -A_{2} & 0 & 0 \\ A_{3} & A_{4} & 0 & 0 \\ 0 & -A_{5} & -A_{6} & A_{7} \\ 0 & A_{8} & A_{9} & -A_{10}\end{array}\right]$,

where

$$
\begin{aligned}
& A_{1}=\left(\frac{1}{\tau^{*}}+\frac{X^{*}}{\left(1+S^{*}\right)^{2}}\right), A_{2}=\frac{S^{*}}{\left(1+S^{*}\right)}, A_{3}=\frac{X^{*}}{\left(1+S^{*}\right)^{2}}, \\
& A_{4}=\left[\frac{R^{*}-1-b_{H}^{*} \tau^{*}}{\tau^{*}}\right]+\frac{S^{*}}{1+S^{*}}, A_{5}=\left(k_{\mathrm{sor}}^{*}+k_{\mathrm{biol}}^{*}\right) C_{s}^{*}, A_{6}=\left(\frac{1}{\tau^{*}}+X^{*}\left[k_{\mathrm{sor}}^{*}+k_{\mathrm{biol}}^{*}\right]\right), \\
& A_{7}=\frac{k_{\mathrm{sor}}^{*}}{K_{d}^{*}}, A_{8}=k_{\mathrm{sor}}^{*} C_{s}^{*}, A_{9}=k_{\mathrm{sor}}^{*} X^{*}, A_{10}=\left(\frac{1-R^{*}}{\tau^{*}}+\frac{k_{\mathrm{sor}}^{*}}{K_{d}^{*}}\right) .
\end{aligned}
$$

\subsubsection{Stability of the washout solution branch}

Along the washout solution branch the eigenvalues of the Jacobian matrix are given by

$$
\begin{aligned}
\lambda_{1,2} & =-\frac{1}{\tau^{*}}<0, \\
\lambda_{3} & =\left[\frac{R^{*}-1-\frac{k_{\text {sor }}^{*}}{K_{d}^{*}} \tau^{*}}{\tau^{*}}\right]<0, \\
\lambda_{4} & =\frac{R^{*}-1-b_{H}^{*} \tau^{*}}{\tau^{*}}+\frac{S_{s, \text { in }}^{*}}{1+S_{s, \text { in }}^{*}} .
\end{aligned}
$$


Note that $0 \leq R^{*}<1$. Rearranging the expression for $\lambda_{4}$ we find that the eigenvalue is negative when

$$
\left[S_{s, \text { in }}^{*}-b_{H}^{*}\left(1+S_{0}^{*}\right)\right] \tau^{*}<\left(1-R^{*}\right)\left(1+S_{s, \text { in }}^{*}\right)
$$

This shows that the eigenvalue is always negative when the decay rate is sufficiently high, i.e. when

$$
b_{H} \geq \frac{S_{s, \text { in }}^{*}}{1+S_{s, \text { in }}^{*}} .
$$

When this inequality does not hold, i.e. when

$$
b_{H}<\frac{S_{s, \text { in }}^{*}}{1+S_{s, \text { in }}^{*}}
$$

the washout steady-state solution is stable when thedimensionless residence time is sufficiently low, i.e. when

$$
\tau^{*}<\tau_{\mathrm{cr}}^{*}=\frac{\left(1+S_{s, \mathrm{in}}^{*}\right)\left(1-R^{*}\right)}{S_{s, \text { in }}^{*}-\left(1+S_{s, \text { in }}^{*}\right) b_{H}^{*}} .
$$

Using standard methods [43] it can be shown that the washout solution branch is globally stable if it is locally stable.

\subsubsection{Stability of the no-washout solution branch}

For any steady-state solution we have from equation (24) that

$$
0=X^{*}\left(\frac{R^{*}-1}{\tau^{*}}+\frac{S^{*}}{1+S^{*}}-b_{H}^{*}\right)
$$

The washout branch corresponds to the solution

$$
0=X^{*}
$$


whereas the no-washout branch corresponds to the solution

$$
0=\frac{R^{*}-1}{\tau^{*}}+\frac{S^{*}}{1+S^{*}}-b_{H}^{*}
$$

Observe that the expression at $J_{2,2}$ is exactly this,

$$
J_{2,2}=\frac{R^{*}-1}{\tau^{*}}+\frac{S^{*}}{1+S^{*}}-b_{H}^{*}
$$

It immediately follows that along the no-washout solution branch we have

$$
J_{2,2}=0
$$

Along this solution branch the characteristic polynomial of the Jacobian matrix (37) is given by

$$
\begin{aligned}
C(\lambda) & =\left[\lambda^{2}+a_{1} \lambda+a_{2}\right]\left[\lambda^{2}+A_{1} \lambda+A_{3} A_{2}\right], \\
a_{1} & =A_{6}+A_{10} \\
a_{2} & =A_{6} A_{10}-A_{7} A_{9} .
\end{aligned}
$$

This solution branch is only of interest when the solution components are all positive. Under these circumstances the coefficients in the Jacobian matrix, $A_{i}, i=1, \cdots 10$, are also positive.

Equation (42) is a product of two quadratic equations. The conditions for the steady-state solution to be locally stable are: $a_{1}>0, a_{2}>0, A_{1}>0$ and $A_{3} A_{2}>0$. The coefficients $a_{1}$, $A_{3} A_{2}$ and $A_{1}$ are immediately seen to be positive. To prove that $a_{2}>0$, we have

$$
a_{2}=A_{6} A_{10}-A_{7} A_{9}=\frac{A_{10}+X^{*} \tau^{*} \frac{k_{\text {sor }}^{*}}{K_{d}^{*}} k_{\mathrm{biol}}^{*}+X^{*}\left[k_{\mathrm{sor}}^{*}+k_{\mathrm{biol}}^{*}\left[1-R^{*}\right]\right.}{\tau^{*}}>0 .
$$

We conclude that when the no-washout branch is physically meaningful, it is stable. 


\subsection{Asymptotic solution along the no-washout solution branch}

At large values of the dimensionless residence time the solution components along the nowashout solution branch are approximated by

$$
\begin{aligned}
S^{*} & \approx \frac{b_{H}^{*}}{1-b_{H}^{*}}+\frac{1-R^{*}}{\left(1-b_{H}^{*}\right)^{2}} \cdot \frac{1}{\tau^{*}}+O\left(\frac{1}{\tau^{* 2}}\right), \\
X^{*} & \approx \frac{S_{s, \text { in }}^{*}-b_{H}^{*}\left(S_{s, \text { in }}^{*}+1\right)}{b_{H}^{*}\left(1-b_{H}^{*}\right)} \cdot \frac{1}{\tau^{*}}+O\left(\frac{1}{\tau^{* 2}}\right), \\
C_{s}^{*} & \approx \frac{b_{H}^{*}\left(1-b_{H}^{*}\right)}{\left[S_{s, \text { in }}^{*}-b_{H}^{*}\left(S_{s, \text { in }}^{*}+1\right)\right] k_{\mathrm{biol}}^{*}+b_{H}^{*}\left(1-b_{H}^{*}\right)}-\frac{\left(1-R^{*}\right)\left[K_{d}^{*} C_{1}-k_{\mathrm{biol}}^{*} C_{2}\right]}{C_{3}^{2}} \cdot \frac{1}{\tau^{*}} \\
& +O\left(\frac{1}{\tau^{* 2}}\right), \\
C_{p}^{*} & \approx \frac{K_{d}^{*}\left[S_{s, \text { in }}^{*}-b_{H}^{*}\left(S_{s, \text { in }}^{*}+1\right)\right]}{k_{\mathrm{sor}}^{*}\left[\left(S_{s, \text { in }}^{*}-b_{H}^{*}\left(S_{s, \text { in }}^{*}+1\right)\right) k_{\mathrm{biol}}^{*}+b_{H}^{*}\left(1-b_{H}^{*}\right)\right]} \cdot \frac{1}{\tau^{*}}+O\left(\frac{1}{\tau^{* 2}}\right), \\
C_{1} & =b_{H}^{*}\left(1-b_{H}^{*}\right)\left[S_{s, \text { in }}^{*}-b_{H}^{*}\left(1+S_{s, \text { in }}^{*}\right)\right]>0, \\
C_{2} & =\left(1-b_{H}^{*}\right)^{2} S_{s, \text { in }}^{*}+b_{H}^{* 2}>0, \\
C_{3} & =-k_{\mathrm{biol}}^{*}\left(1-b_{H}^{*}\right) S_{s, \text { in }}^{*}-b_{H}^{*}\left(1-b_{H}^{*}-k_{\mathrm{biol}}^{*}\right) .
\end{aligned}
$$

Note that from equation (32) that this solution branch is only meaningful when $b_{H}^{*}<\frac{S_{s, \text { in }}^{*}}{1+S_{s, \text { in }}^{*}}$. Thus we have, $\left[S_{s, \text { in }}^{*}-b_{H}^{*}\left(1+S_{s, \text { in }}^{*}\right)\right]>0$. Equations (43 and 45$)$ show that the dimensionless effluent concentration and the dimensionless soluble micropollutant concentration reach limiting value at large dimensionless residence times,

$$
\begin{aligned}
\lim _{\tau^{*} \rightarrow+\infty} S^{*} & =\frac{b_{H}^{*}}{1-b_{H}^{*}}>0, \\
\lim _{\tau^{*} \rightarrow+\infty} C_{s}^{*} & =\frac{b_{H}^{*}\left(1-b_{H}^{*}\right)}{\left[S_{s, \text { in }}^{*}-b_{H}^{*}\left(S_{s, \text { in }}^{*}+1\right)\right] k_{\text {biol }}^{*}+b_{H}^{*}\left(1-b_{H}^{*}\right)}>0 .
\end{aligned}
$$

These limiting concentrations are independent of the values associated with the adsorption $\left(k_{\text {sor }}^{*}\right)$ and desorption $\left(K_{d}^{*}\right)$ processes.

It can be noted from equation (48) that when there is no biological reaction $\left(k_{\text {biol }}^{*}=0\right)$, that the limiting value of the dimensionless soluble micropollutant concentration is equal to the dimensionless influent concentration,

$$
\lim _{\tau^{*} \rightarrow+\infty} C_{s}^{*}\left(k_{\mathrm{biol}}^{*}=0\right)=1
$$


The reason for this is as follows: when $k_{\text {biol }}^{*}=0$ there is no biological removal of the micropollutant. The only removal mechanism for the micropollutant is through adsorption onto the microorganisms. However, in the limit of the large residence times, equation (44) shows that the microorganism concentration approaches zero. Consequently, there are no microorganisms to be absorbed onto.

When the micropollutant is not biodegradable the concentration of soluble micropollutants along the no-washout branch simplifies to

$$
C_{s}^{*}\left(\tau^{*}\right)=\frac{1-R^{*}+k_{\mathrm{sor}}^{*} \tau^{*} / K_{d}^{*}}{1-R^{*}+k_{\mathrm{sor}}^{*} \tau^{*} / K_{d}^{*}+\left(1-R^{*}\right) k_{\mathrm{sor}}^{*} X\left(\tau^{*}\right) \tau^{*}}, \quad \tau_{\mathrm{cr}}^{*} \leq \tau^{*}
$$

This is a continuous function with value $C_{s}^{*}=1$ when $\tau^{*}=\tau_{\text {cr }}^{*}$ and limiting value $\lim _{\tau^{*} \rightarrow \infty} C_{s}^{*}=$ 1. As $C_{s}^{*}<1$ for $\tau_{\mathrm{cr}}^{*}<\tau^{*}<\infty$ we conclude that, when the micropollutant is non-biodegradable, there must be a finite value of the dimensionless residence which minimises its value. This is an interesting finding that has not been reported previously.

Note from equation (45) that if the term $\left(K_{d}^{*} C_{1}-k_{\text {biol }}^{*} C_{2}\right)$ is positive (negative) then the soluble micropollutant concentration increases (decreases) to its limiting value. This shows that in the former case the concentration of soluble micropollutant is minimized at a finite residence time. This case happens when

$$
\frac{K_{d}^{*}}{k_{\mathrm{biol}}^{*}}>\frac{\left[\left(1-b_{H}^{*}\right)^{2} S_{s, \text { in }}^{*}+b_{H}^{*^{2}}\right]}{b_{H}^{*}\left(1-b_{H}^{*}\right)\left[S_{s, \text { in }}^{*}-b_{H}^{*}\left(1+S_{s, \text { in }}^{*}\right)\right]}
$$

This behavior can not occur in the limit $b_{H}^{*}=0$.

The right hand side of inequality (50) only depends upon the values of $S_{s, \text { in }}^{*}$ and $b_{H}^{*}$. Using the parameter values in table (3), we find that the right hand side is equal to 27.38089632. In table (7), we calculate the LHS of the inequality (50) for each of the 11 micropollutants. We observe that only non-biodegradable micropollutants (CBZ and DZP) satisfy inequality (50), thus these are the only micropollutants that increase to their limiting value.

Equations (44 and 46) show that both the dimensionless microorganism concentration and the dimensionless particulate micropollutant concentration decrease to zero.

We note that the limiting value of all solution components is independent of the effective recycle ratio $\left(R^{*}\right)$. In equations $(43)-(46)$ the recycle ratio only influences, as a second-order 
effect, the concentrations of the soluble substrate and the soluble micropollutant. When the micropollutant is not biodegradable $\left(k_{\text {biol }}^{*}=0\right)$, we have from equation (45) that

$$
\left.\frac{d C_{s}^{*}}{d R^{*}}\right|_{k_{\mathrm{biol}}^{*}=0}=\frac{\left[S_{s, \text { in }}^{*}-b_{H}^{*}\left(1+S_{s, \text { in }}^{*}\right)\right]}{b_{H}^{*} \tau^{*}\left(1-b_{H}^{*}\right)} \cdot K_{d}^{*} \cdot \frac{1}{\tau^{*}}>0 .
$$

This shows that when the micropollutant is not biodegradable that recycle increases the concentration of soluble micropollutants at large residence times.

\subsection{Steady-state diagrams: No settling unit}

In this section we investigate steady-state diagrams when there is no settling unit $\left(R=R^{*}=0\right)$. Although this is not realistic from the perspective of an ASP plant, it does model another treatment method: the aerated lagoon. In any case this section provides a baseline for evaluating the effect of recycle.

Steady state diagrams for eleven micropollutants are shown in figure (2). It is assumed that there is no recycle. The micropollutants considered are those investigated in [7]. These compounds represent four possible types of micropollutants behaviour [7]. These are i) highly biodegradable with low sorption; ii) highly biodegradable with high sorption; iii) slowly biodegradable; and iv) non biodegradable.

The soluble micropollutant concentration is equal to one along the washout branch $\left(\tau^{*}<\right.$ $\left.\tau_{\mathrm{cr}}^{*}=1.146\right)$. After the transcritical bifurcation, the concentration of soluble micropollutants initially decreases. At sufficiently high residence times it may increase to its limiting value. This depends upon the sign of coefficient of the term $\tau^{*}$ in equation (45). For non-biodegradable compounds, equation (51) shows that the soluble micropollutants decreases to minimum point before increasing to its asymptotic value.

It can be noted from equation (45) that the concentration of soluble micropollutants approaches the limiting value,

$$
\lim _{\tau^{*} \rightarrow+\infty} C_{s}^{*}= \begin{cases}\frac{b_{H}^{*}\left(1-b_{H}^{*}\right)}{\left[S_{s, \text { in }}^{*}-b_{H}^{*}\left(S_{s, \text { in }}^{*}+1\right)\right] k_{\text {biol }}^{*}+b_{H}^{*}\left(1-b_{H}^{*}\right)} & k_{\text {biol }}^{*}>0 \\ 1 & k_{\text {biol }}^{*}=0 .\end{cases}
$$

Figure 2(d) shows, as noted in section (4.4), that if the micropollutant is non-biodegradable then 


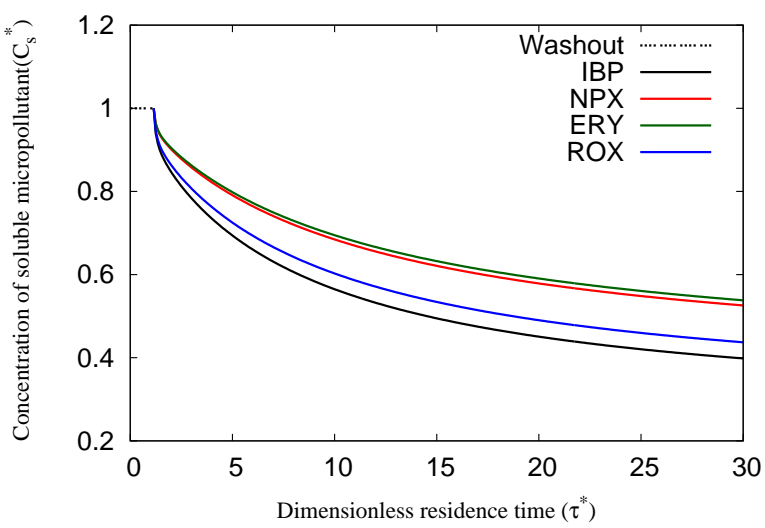

(a) Highly biodegradable with low sorption.

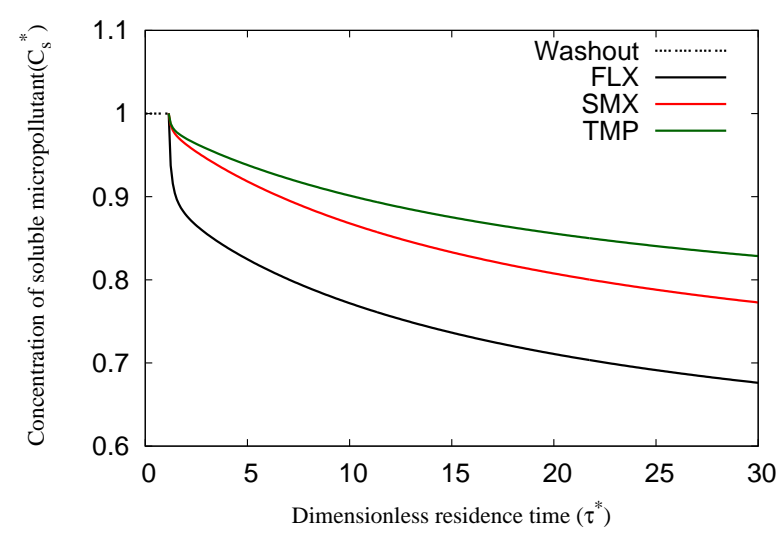

(c) Slowly biodegradable.

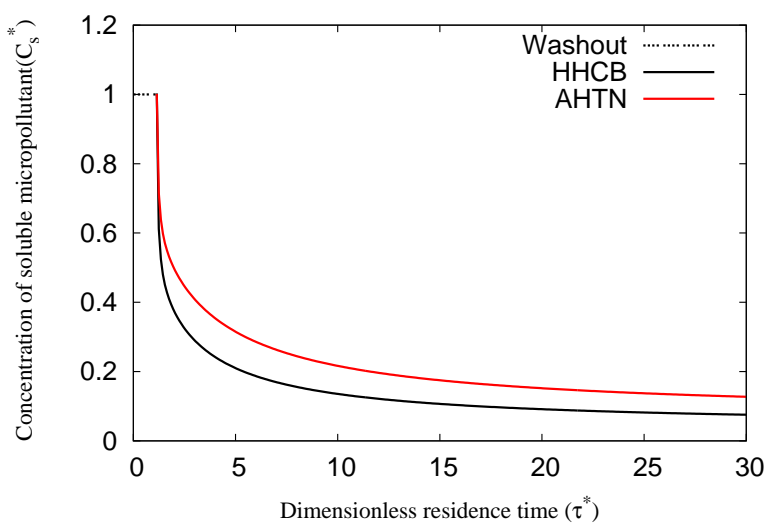

(b) Highly biodegradable with high sorption.

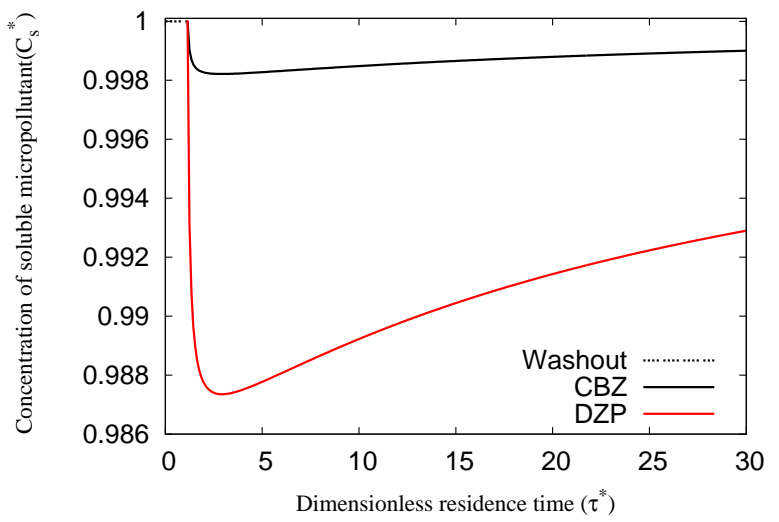

(d) Non biodegradable.

Figure 2: Steady-state diagrams for the dimensionless soluble micropollutant concentration when there is no settling unit $\left(R^{*}=0\right)$. In $(\mathrm{d})$ the concentrations of CBZ and DZP are minimised at dimensionless residence times $\tau^{*}=2.91$ and $\tau^{*}=2.92$, respectively. The washout line corresponds to process failure as there is no active biomass in the bioreactor $\left(X^{*}=0\right)$. Parameter values stated in tables 3 and 4 .

the soluble micropollutant concentration approaches the value in the influent at large residence times. The limiting value of the soluble micropollutant concentration for all compounds is presented in table (5). The limiting soluble micropollutants concentration is only influenced by one parameter associated with the micropollutants $\left(k_{\text {biol }}^{*}\right)$ and two parameter associated with activated sludge $\left(b_{H}^{*}\right.$ and $\left.S_{s, \text { in }}^{*}\right)$. Note that the limiting soluble micropollutant concentration can be decreased by increasing the influent substrate concentration $\left(S_{s, \text { in }}^{*}\right)$.

From equation (34) we know that as the biotransformation kinetic constant $\left(k_{\text {biol }}\right)$ increases, the concentration of soluble micropollutant decreases. Suppose that we specify a desired maximum concentration of the micropollutant in the effluent $\left(0<C_{s, e}^{*}<1\right)$. Then at high residence 
times, equation (45) gives the requirement that

$$
k_{\mathrm{biol}}^{*}>\frac{b_{H}^{*}\left(1-C_{s, e}^{*}\right)\left(1-b_{H}^{*}\right)}{C_{s, e}^{*}\left[S_{s, \text { in }}^{*}-b_{H}^{*}\left(S_{s, \text { in }}^{*}+1\right)\right]} .
$$

In practise, it may not be possible to increase the value for biotransformation constant $k_{\text {biol }}^{*}$. However, increasing the substrate concentrations in the feed has an equivalent effect.

Figure 2(b) shows that the removal of the micropollutant is optimized when it is highly biodegradable with high sorption while the removal of the micropollutant decreases if it is slowly biodegradable, as in figure 2(c). Figure 2(d) demonstrates that when the micropollutant is not biodegradable its concentration is minimised at a finite value of the residence time. At this point, the removal of CBZ and DZP are $0.1785 \%$ and $1.265 \%$, respectively. Thus there is an insignificant removal of these non-biodegradable compounds.

Figure 3 shows the steady-state particulate micropollutant concentration when there is no recycle. Along the no washout branch, the concentration increases sharply from its initial zero value to reach a maximum value. These maximum values are shown in table 5 . After the maximum value, the concentration decreases towards a limiting value, given by equation (46) when the residence time approaches infinity.

For non-biodegradable micropollutant shown in figure $(3(d))$, the maximum particulate micropollutant concentration are very low. This accounts for the negligible removal of soluble micropollutant shown in figure $(2(d))$

\subsection{Steady-state diagrams: The effect of recycle}

We now investigate how the particulate micropollutant concentration and the soluble micropollutant concentration change in response to the deployment of a settling unit. We pick one example of each of the four classes of micropollutants: IBP, HHCB, FLX and DZP. We show that when the micropollutant is biodegradable, recycle decreases the soluble concentration of micropollutants at intermediate value of the residence time. However, equation (45) shows that recycle does not change the limiting value for the soluble concentration of micropollutants.

Figure 4 shows the soluble micropollutants concentrations for four values of the effective recycle ratio $\left(R^{*}=0,0.5,0.9,0.99\right)$.

Figures 4(a)-4(c) show that concentration of biodegradable micropollutants reduces as the 


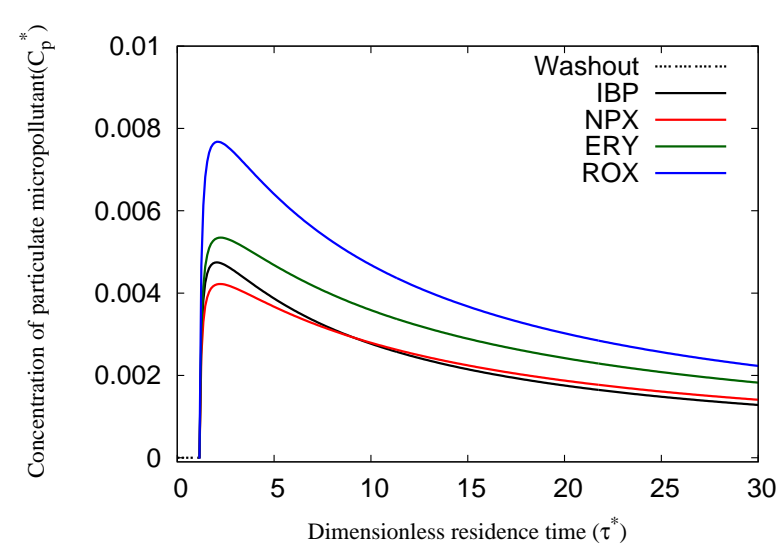

(a) Highly biodegradable with low sorption.

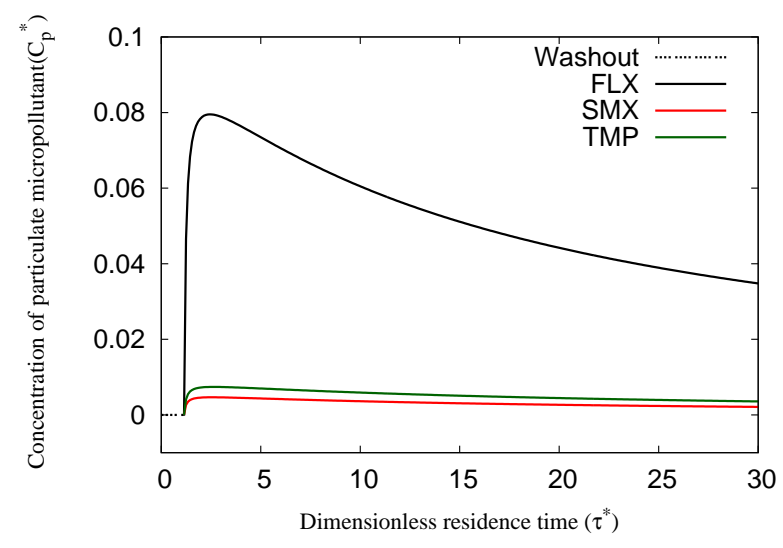

(c) Slowly biodegradable.

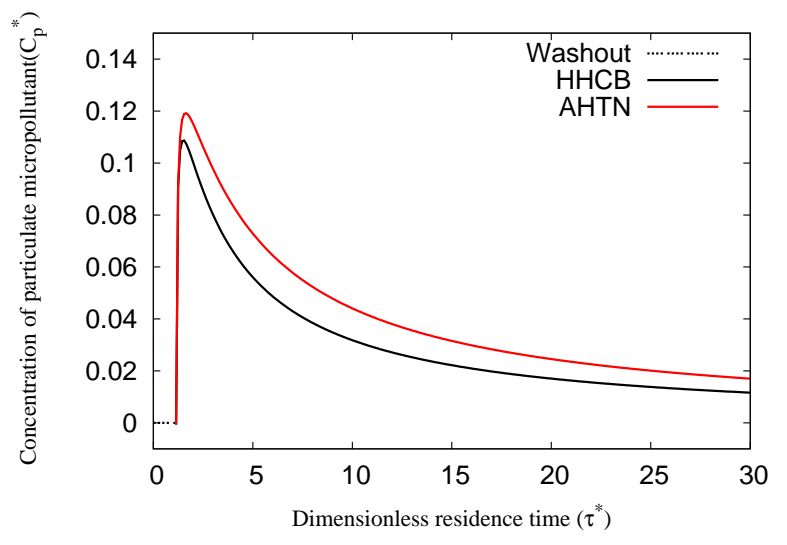

(b) Highly biodegradable with high sorption.

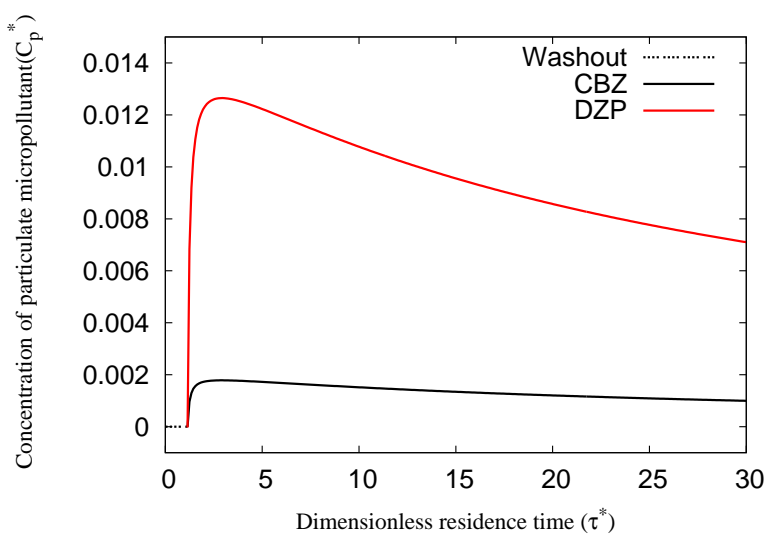

(d) Non biodegradable.

Figure 3: Steady-state diagrams for the dimensionless particulate micropollutants concentration when there is no settling unit $\left(R^{*}=0\right)$. The washout line corresponds to process failure as there is no active biomass in the bioreactor $\left(X^{*}=0\right)$. Parameter values stated in tables 3 and 4 . 
Table 5: The maximum value for the dimensionless particulate micropollutant concentration $\left(C_{p}^{*}\right)$ and the limiting value for the dimensionless soluble micropollutant concentration $\left(C_{s}^{*}\right)$.

\begin{tabular}{lccc}
\hline Compound & $\tau_{\max }^{*}$ & $C_{p, \max }^{*}$ & $C_{s}^{*}\left(\tau^{*} \rightarrow \infty\right)$ \\
\hline Highly biodegradable with low sorption & & & \\
\hline Ibuprofen IBP & 2.039170150 & 0.004746277070 & 0.2571859399 \\
Naproxen NPX & 2.211854462 & 0.004221603347 & 0.3672104430 \\
Erythromycin ERY & 2.240487043 & 0.005347715078 & 0.3790339725 \\
Roxithromycin ROX & 2.091847994 & 0.007677084631 & 0.2892322665 \\
\hline Highly biodegradable with high sorption & & & \\
\hline Galaxolide HHCB & 1.504058798 & 0.1087880050 & 0.04135869573 \\
Tonalide AHTN & 1.621318123 & 0.1192251535 & 0.07203686271 \\
\hline Slowly biodegradable & & & \\
\hline Fluoxetine FLX & 2.451501517 & 0.07951528778 & 0.5497094053 \\
Sulfamethoxazole SMX & 2.559780775 & 0.004659700831 & 0.6417534698 \\
Trimethoprim TMP & 2.646265867 & 0.007404355386 & 0.7202875387 \\
\hline Non biodegradable & & & \\
\hline Carbamazepine CBZ & 2.907595370 & 0.001785309061 & 1 \\
Diazepam DZP & 2.920086511 & 0.01264770350 & 1
\end{tabular}

effective recycle ratio is increased. Thus, recycle has a positive effect in reducing the soluble micropollutant concentration. (At sufficiently high values of the residence time the concentration may increase, see discussion of equation (50)).

Figure 4(d) illustrates the case when the micropollutant is not biodegradable. In this case we obtain a surprising result, namely that the minimum value of the soluble micropollutants concentrations is obtained when there is no recycle. This is confirmed by the values shown in table (6). However, in practise this effect likely to be insignificant due to the negligible removal of non-biodegradable micropollutant. Only when the reactor is operated at residence times lower than than that at washout $\left(\tau^{*}<\tau_{\mathrm{cr}}^{*}\left(R^{*}=0\right)\right)$, does recycle have a positive effect in reducing the soluble micropollutant concentration.

Figure 5 shows how the recycle effects the particulate micropollutant concentration for the same value of the effective recycle ratio $\left(R^{*}=0,0.5,0.9,0.99\right)$. In all cases, the particulate micropollutants concentration increases as the recycle increases. This is expected, as increasing the effective recycle parameter decreases the amount of particulate matter that is discharged in the waste stream and thereby increasing the amount in the reactor.

Our asymptotic result revealed that the concentration of non-biodegradable micropollutants is minimised at a finite value of the residence time. This is showing in figure $(2(\mathrm{~d}))$. Figure 6 
Table 6: The dependence of the minimum value of the dimensionlesssoluble micropollutant concentration $\left(C_{s}^{*}\right)$ upon the effective recycle parameterfor DZP.

\begin{tabular}{lcc}
\hline$R^{*}$ & $\tau_{\min }^{*}$ & $C_{s, \min }^{*}$ \\
\hline 0 & 2.9201 & 0.9873522979 \\
0.5 & 1.4600 & 0.9873522977 \\
0.9 & 0.2920 & 0.9873523123 \\
0.99 & 0.0292 & 0.9873539515 \\
\hline
\end{tabular}

shows a curve in the $K_{d}-k_{\text {sor }}$ parameter space along which the minimum soluble micropollutant concentration is equal to 0.1 , representing $90 \%$ removal of the micropollutant. In the region above the curve the minimum soluble micropollutant concentration is less than 0.1 . Thus, $90 \%$ removal of the micropollutant is only possible for parameter values above the curve. In the region below the curve, the minimum soluble micropollutant concentrations is greater than 0.1. Note that this figure is plotted using the dimensional values, $K_{d}$ and $k_{\text {sor }}$, rather than dimensionless values, $K_{d}^{*}$ and $k_{\mathrm{sor}}^{*}$, to facilitate comparison with the typical values for nonbiodegradable micropollutants show in table (4). From this comparison we conclude that $90 \%$ removal of non-biodegradable micropollutants is impossible. Finally, we note that recycle has a negligible effect on the demarcation line as indicated in table (6).

Figure 7 shows curves in the $K_{d^{-}} k_{\text {sor }}$ parameter space for non-biodegradable micropollutants along which the soluble micropollutant concentration is equal to 0.5 , representing $50 \%$ removal of the micropollutant, for different value of the effective recycle ratio. In the region above the curve the soluble micropollutant concentration is less than 0.5 . Thus, $50 \%$ removal of the micropollutant is only possible for parameter values above the curve. In the region below the curve, the soluble micropollutant concentrations is greater than 0.5 . It can be noted that recycle now has a significant effect on the location of the boundary.

\subsection{Which removal mechanism is the most effective?}

At steady state the rate at which soluble micropollutants enter the reactor $\left(D_{1}\right)$ is given by

$$
D_{1}=\frac{1}{\tau^{*}}+\frac{k_{\mathrm{sor}}^{*}}{K_{d}^{*}} C_{p}^{*}
$$




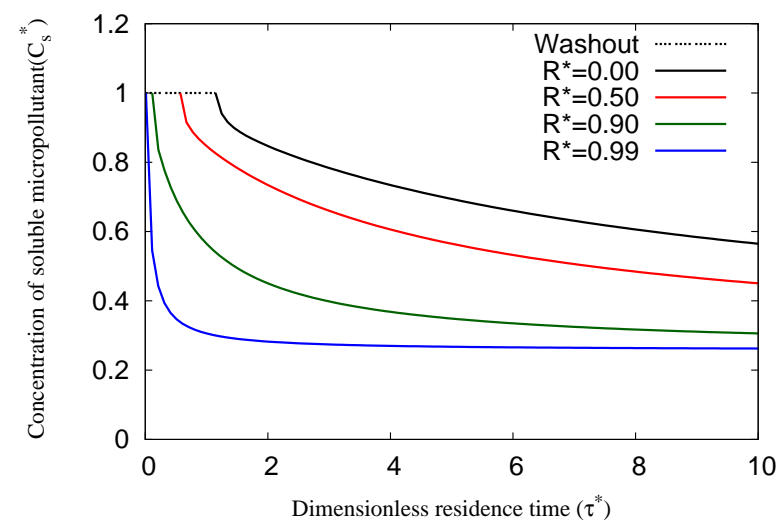

(a) Highly biodegradable with low sorption (IBP).

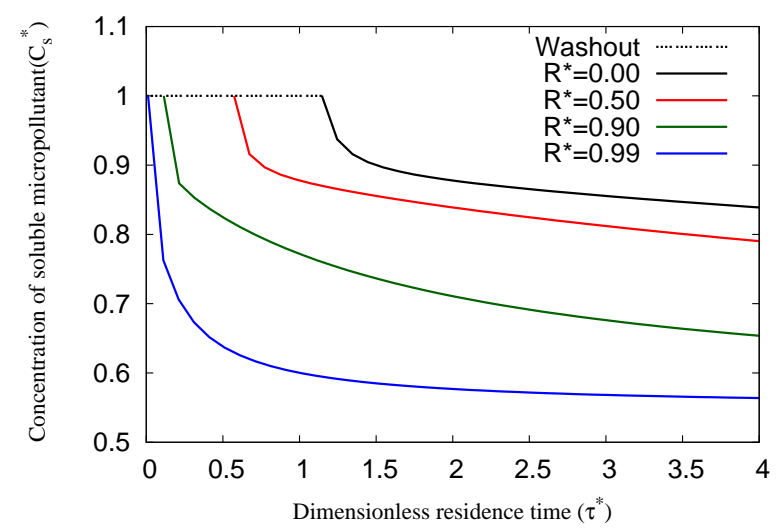

(c) Slowly biodegradable (FLX).

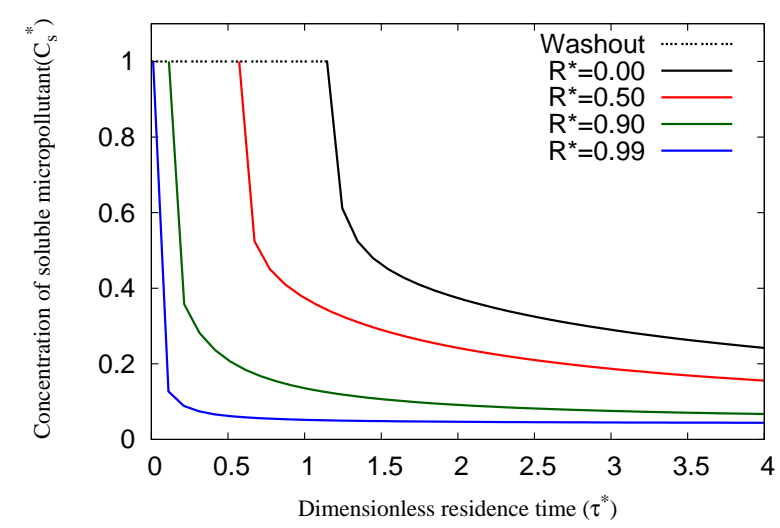

(b) Highly biodegradable and sorption (HHCB).

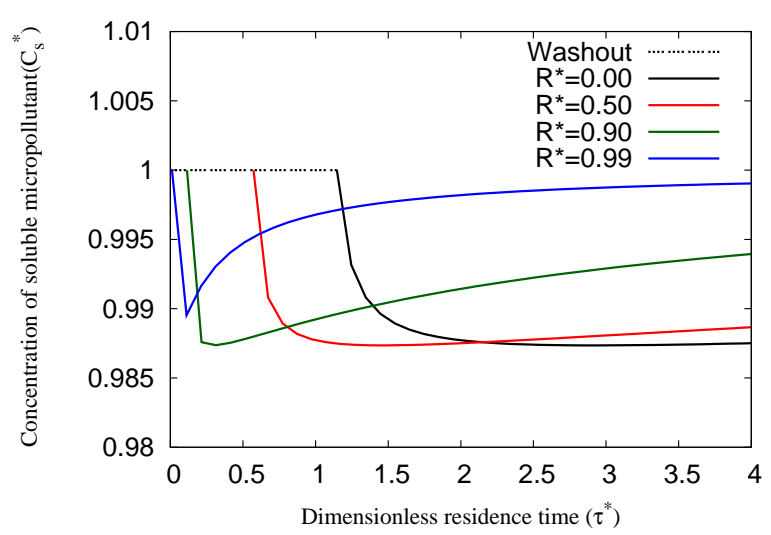

(d) Non biodegradable (DZP).

Figure 4: Steady-state diagrams for the dimensionless soluble micropollutants concentration. as a function of the effective recycle ratio. In each diagram the 'top' curve, i.e. the curve with the lowest value of the dimensionless residence time at the transcritical bifurcation, corresponds to the case $R^{*}=0.0$ and the 'bottom' curve, i.e. the curve with the highest value of the dimensionless residence time at the transcritical bifurcation, corresponds to the case $R^{*}=0.99$. The washout line corresponds to process failure as there is no active biomass in the bioreactor $\left(X^{*}=0\right)$. Parameter values stated in tables 3 and 4 . 


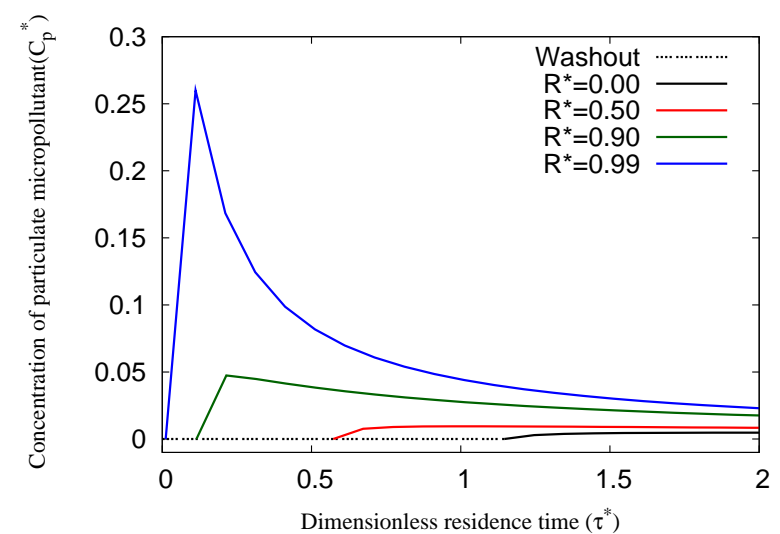

(a) Highly biodegradable with low sorption (IBP).

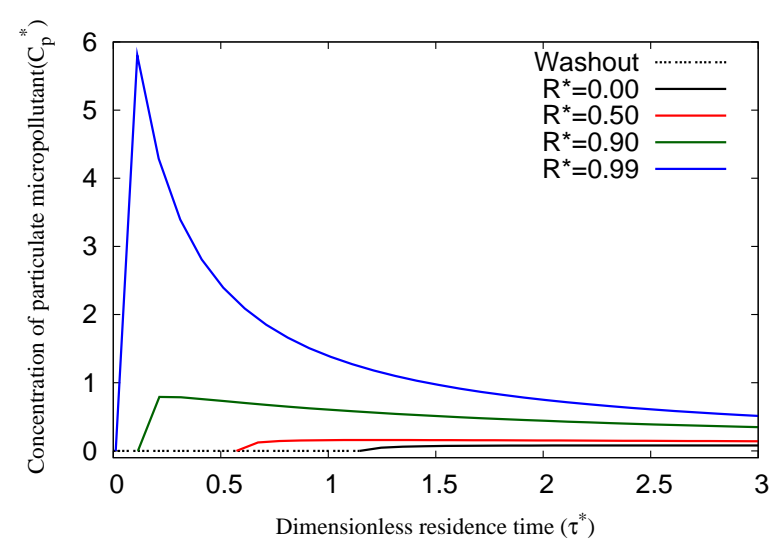

(c) Slowly biodegradable (FLX).

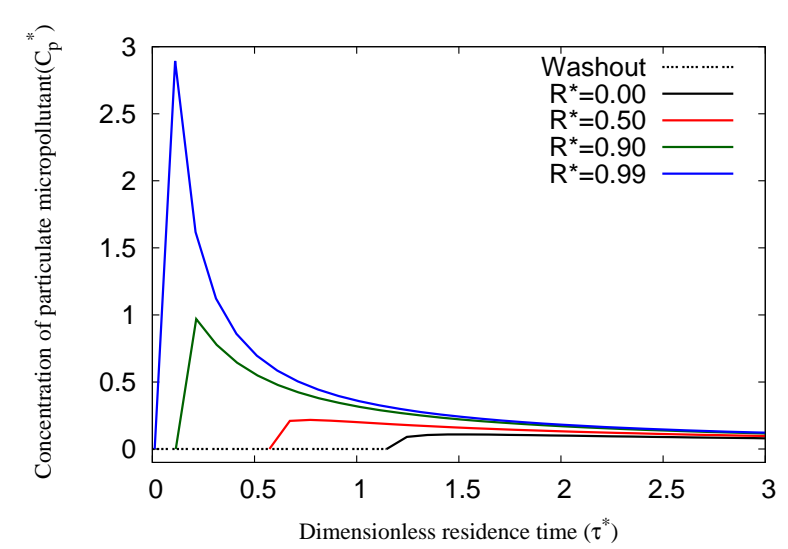

(b) Highly biodegradable and sorption (HHCB).

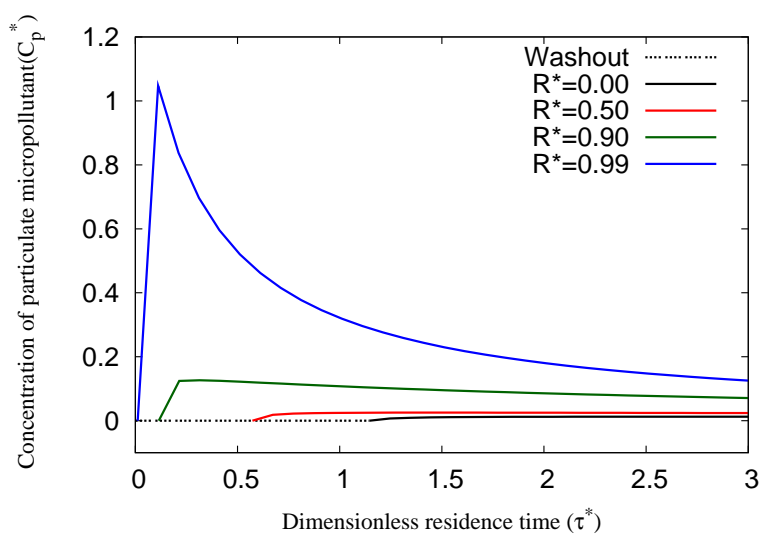

(d) Non biodegradable (DZP).

Figure 5: Steady-state diagrams for the dimensionless particulate micropollutant concentration as a function of the effective recycle ratio. In each diagram the 'top' curve corresponds to the case $R^{*}=0.99$ and the 'bottom' curve corresponds to the case $R^{*}=0$. The washout line corresponds to process failure as there is no active biomass in the bioreactor $\left(X^{*}=0\right)$. Parameter values stated in tables 3 and 4 . 


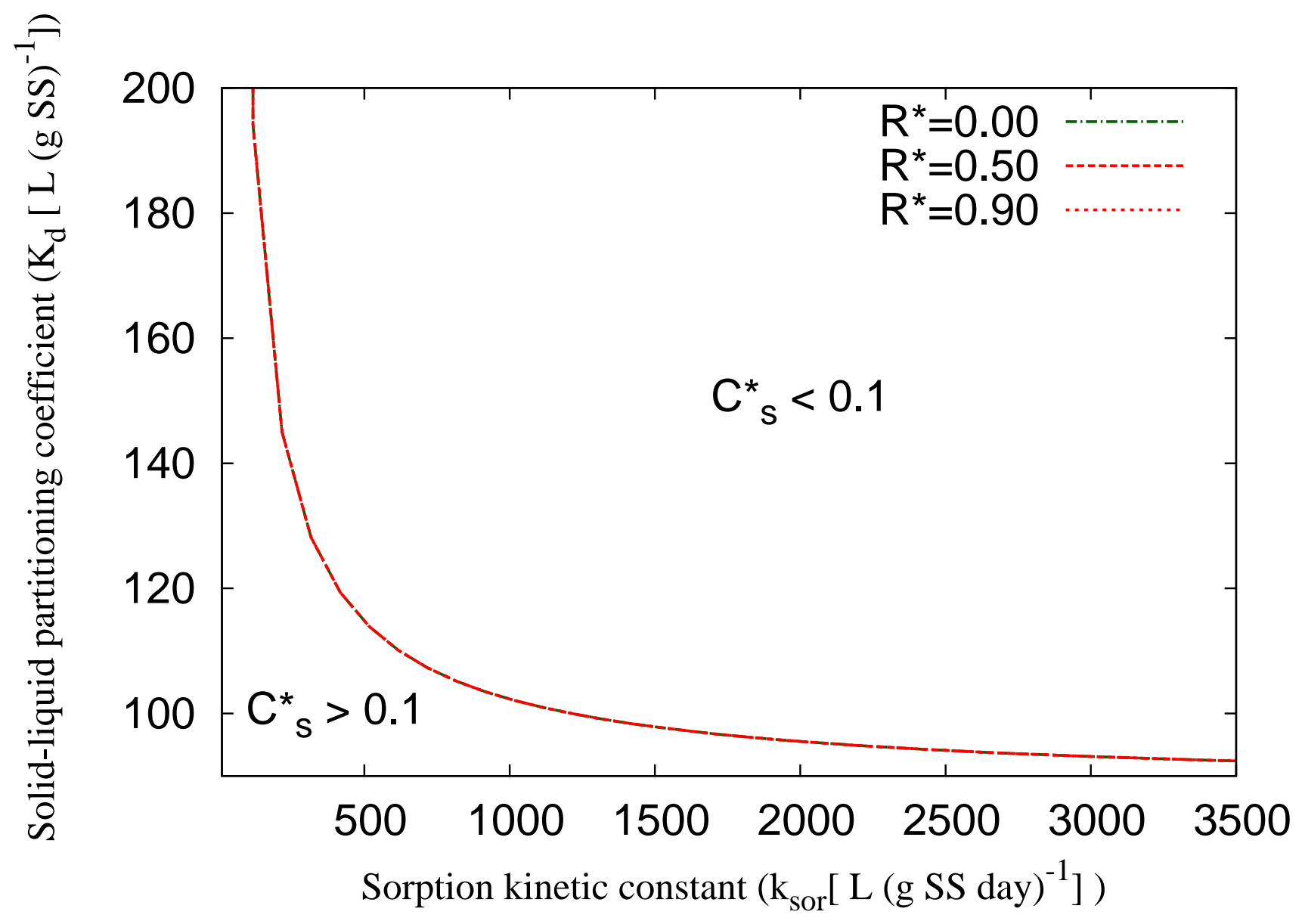

Figure 6: Diagram showing that the effective recycle ratio $\left(R^{*}\right)$ has a negligible effect upon the locus $C_{s, \text { min }}^{*}=0.1$ in the $K_{d}\left[\mathrm{~L}(\mathrm{~g} \mathrm{SS})^{-1}\right]-k_{\text {sor }}\left[\mathrm{L}(\mathrm{g} \mathrm{SS} \text { day })^{-1}\right]$ plane for non-biodegradable micropollutants. For any point on the locus, there is a value of the residence time at which the minimum soluble micropollutant concentration is 0.1 . Parameter values stated in tables 3 and 4. 


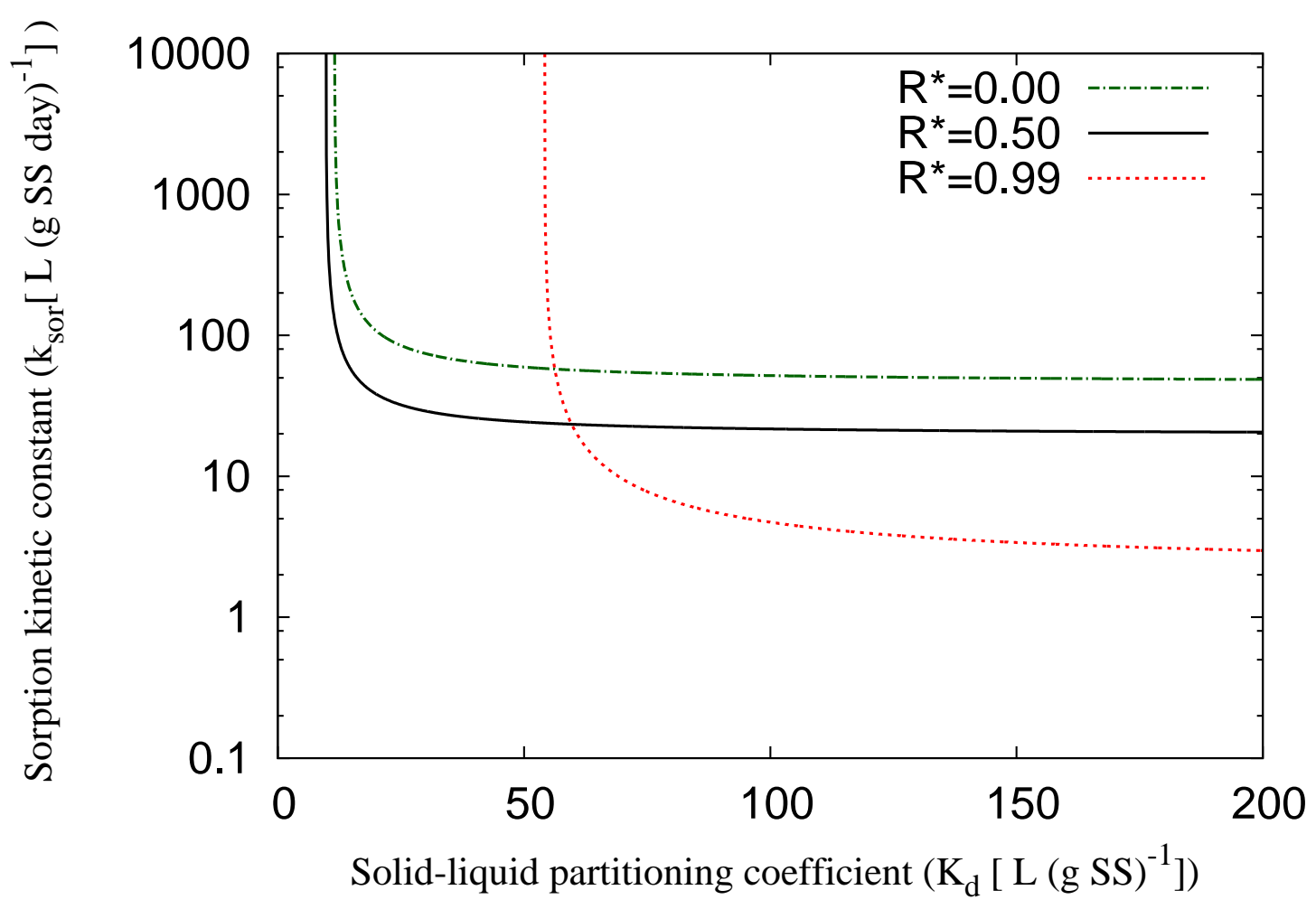

Figure 7: Diagram showing how the locus $C_{s}^{*}=0.5$ in the $K_{d}\left[\mathrm{~L}(\mathrm{~g} \mathrm{SS})^{-1}\right]-k_{\text {sor }}\left[\mathrm{L}(\mathrm{g} \text { SS day })^{-1}\right]$ plane for non-biodegradable micropollutant depends upon the value of the effective recycle ratio $\left(R^{*}\right)$. For any point on the locus, there is a value of the residence time at which the minimum soluble micropollutant concentration is 0.5. Parameter values stated in tables 3 and 4 . 
This expression contains two terms. The first term on the RHS of the equation is the rate at which soluble micropollutants enter the reactor in the feed. The second term on the RHS is the rate at which micropollutants are generated inside the reactor due to desorption from particulates. There are three processes which lead to a decrease in the concentration of soluble micropollutants.

Rate at which soluble micropollutants leave the reactor in the effluent stream

$$
D_{2}=\frac{C_{s}^{*}}{\tau^{*}}
$$

Rate at which soluble micropollutants are adsorbed onto particulates

$$
D_{3}=k_{\mathrm{sor}}^{*} C_{s}^{*} X^{*}
$$

Rate at which soluble micropollutants are biodegraded

$$
D_{4}=k_{\mathrm{biol}}^{*} X^{*} C_{s}^{*}
$$

At steady-state we have

$$
D_{1}=D_{2}+D_{3}+D_{4}
$$

We define the percentage removed in the effluent stream $(C)$, the percentage removed by adsorption $(B)$ and the percentage removed by biodegradation $(A)$,

$$
\begin{aligned}
& A=100 \frac{D_{4}}{D_{1}}, \\
& B=100 \frac{D_{3}}{D_{1}}, \\
& C=100 \frac{D_{2}}{D_{1}},
\end{aligned}
$$


Figure 8 shows how the percentage removal for each mechanism changes as the dimensionless residence time is changed. Whilst the removal percentage due to biodegradation $(A)$ and due to adsorption $(B)$ are both increasing functions of the residence time the removal percentage in the effluent stream $(C)$ decreases.

In the vicinity of the washout point the most important removal mechanism is removal in the effluent stream (mechanism $\mathrm{C}$ ). At slightly higher values of the residence time the most important removal mechanism is adsorption (mechanism B). This is noteworthy as in table 4 IBP is classified as being highly biodegradable with low sorption. In fact, for the parameter values used in this figure biodegradation (mechanism A) is insignificant, never being more than $5.1 \%$. Even at the residence time $\tau^{*}=10$, we have $A \approx 5.1 \%$. In fact, the percentage removed through adsorption is always higher than that removed by biodegradation.

There is a simple explanation for this finding. The ratio of the percentage removal rate for biodegradation to the percentage removal rate for adsorption is

$$
\frac{D_{4}}{D_{3}}=\frac{k_{\mathrm{biol}}^{*}}{k_{\mathrm{sor}}^{*}}
$$

Thus biodegradation is only more effective than adsorption if $k_{\mathrm{biol}}^{*}>k_{\mathrm{sor}}^{*}$.

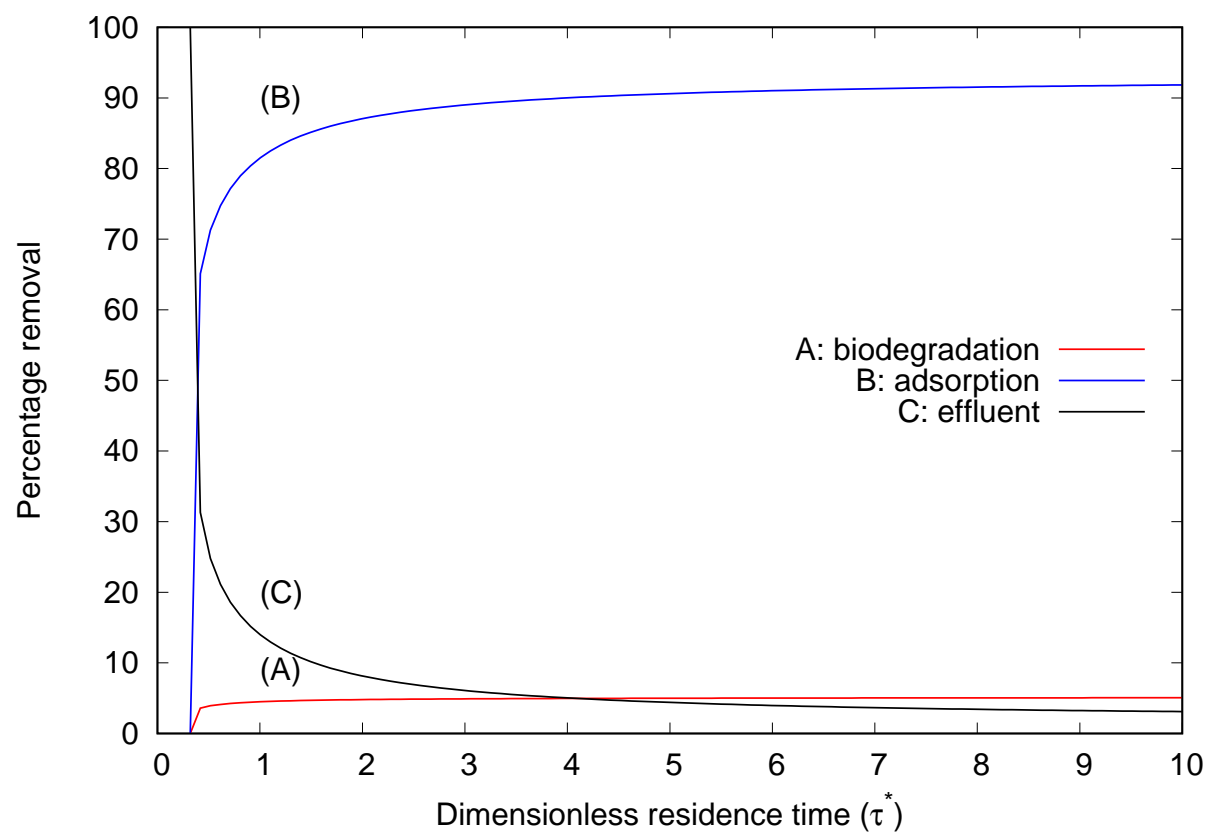

Figure 8: The percentage removal of soluble IBP due to: biodegradation $\left(A=100 \frac{D_{4}}{D_{1}}\right)$, adsorption $\left(B=100 \frac{D_{3}}{D_{1}}\right)$, and removal in the effluent stream $\left(C=100 \frac{D_{2}}{D_{1}}\right)$. The values of the recycle parameter and wastage fraction are $R=0.4$ and $w=0.1$, respectively. Parameter values stated in tables 3 and 4 . 
Table 7: The dimensionless value of the micropollutants biotransformation parameters.

\begin{tabular}{lcccc}
\hline Compound & $k_{\text {biol }}^{*}$ & $K_{d}^{*}$ & $k_{\text {sor }}^{*}$ & $\frac{K_{d}^{*}}{k_{\text {biol }}^{*}}$, Eq $(50)$ \\
\hline Highly biodegradable & & & & \\
with low sorption & & & & \\
\hline Ibuprofen (IBP) & 0.01063066 & 0.00068139 & 0.19296000 & 0.064096638 \\
Naproxen (NPX) & 0.00634266 & 0.00056682 & 0.26029500 & 0.089366197 \\
Erythromycin (ERY) & 0.00603000 & 0.00071757 & 0.07236000 & 0.11900000 \\
Roxithromycin (ROX) & 0.00904500 & 0.00107937 & 0.47536500 & 0.11933333 \\
\hline Highly biodegradable & & & & \\
with high sorption & & & & \\
\hline Galaxolide (HHCB) & 0.08531333 & 0.03261627 & 6.1033650 & 0.38231151 \\
Tonalide (AHTN) & 0.04741366 & 0.02829276 & 2.2964250 & 0.59672162 \\
\hline Slowly biodegradable & & & & \\
\hline Fluoxetine (FLX) & 0.00301500 & 0.01088415 & 4.1697450 & 3.6100000 \\
Sulfamethoxazole (SMX) & 0.00205466 & 0.00057888 & 0.14974500 & 0.28173913 \\
Trimethoprim (TMP) & 0.00142933 & 0.00091053 & 0.19396500 & 0.63703125 \\
\hline Non biodegradable & & & & \\
\hline Carbamazepine (CBZ) & 0 & 0.00021105 & 0.08743500 & $\infty$ \\
Diazepam (DZP) (DZP) & 0 & 0.00151353 & 0.24622500 & $\infty$ \\
& & & & $\infty$ \\
& 0 & & & $\infty$ \\
& & & & \\
\end{tabular}

At large residence times the percentage removal by each mechanism is approximately

$$
\begin{aligned}
& A \approx 100 \xi\left[S_{s, \mathrm{in}}^{*}-b_{H}^{*}\left(S_{s, \mathrm{in}}^{*}+1\right)\right] k_{\mathrm{biol}}^{*}+O\left(\frac{1}{\tau^{*}}\right) . \\
& B \approx 100 \xi\left[S_{s, \mathrm{in}}^{*}-b_{H}^{*}\left(S_{s, \mathrm{in}}^{*}+1\right)\right] k_{\mathrm{sor}}^{*}+O\left(\frac{1}{\tau^{*}}\right) \\
& C \approx 100 \xi b_{H}^{*}\left(1-b_{H}^{*}\right)+O\left(\frac{1}{\tau^{*}}\right)
\end{aligned}
$$

where,

$$
\xi=\frac{1}{\left[S_{s, \text { in }}^{*}-b_{H}^{*}\left(S_{s, \text { in }}^{*}+1\right)\right]\left[k_{\mathrm{biol}}^{*}+k_{\mathrm{sor}}^{*}\right]+b_{H}^{*}\left(1-b_{H}^{*}\right)} .
$$

\section{Conclusion}

We have formulated a mathematical model for the activated sludge process which included the main mechanisms for the removal of micropollutants: biological removal due to biodegradation and/or cometabolism, volatilisation and sorption. We considered a simplified model for biotransformation with no cometabolism and representing the rate of biodegradation as a linear function of the concentration of micropollutants.

As experimental evidence indicates that in many circumstances volatilisation plays only a 
minor role in removing micropollutants we set the appropriate term in our model to zero prior to our analysis. Analytical formulae for the steady-state solutions were then found and their stability determined as a function of the residence time (hydraulic retention time). Asymptotic solutions for large residence times were provided.

Our steady-state results were used to analysis the the removal of soluble micropollutants. The analysis showed that the removal of soluble micropollutant is optimized when they are highly biodegradable with high sorption. We have shown that in the limit of infinitely large residence time that the concentration of biodegradable micropollutants is independent of the parameter values associated with the processes of adsorption and desorption. The limiting concentration can be minimised by either increasing the value of the biological degradation kinetic constant or concentrating the substrate in the feed. Thus the removal of biodegradable pollutants can be enhanced by concentrating the feed.

Our asymptotic results show that it is possible that the soluble micropollutant concentration approaches its limiting value from below. For such a compound there is a finite value of the residence time that optimises its removal. None of the nine biodegradable micropollutants considered in this study behaved in such a manner.

It follows from our asymptotic results that the removal of non-biodegradable pollutants is optimized at a finite value of the residence times, as in the limit of infinite residence times their value approaches that of the influent.

We found that the use of a settling unit enhances the removal of biodegradable micropollutants, see figure $4(\mathrm{a}-\mathrm{c})$. However, the use of a settling unit only enhanced the removal of non-biodegradable micropollutants if the residence time is sufficiently low, see figure 4 (d). However, in the limit of infinite residence time the value of the soluble micropollutant concentration is independent of the operation of a settling unit. For non-biodegradable micropollutants we found a surprising result, namely that the maximum amount of micropollutant removed may be a decreasing function of the effective recycle ratio. The removal of such micropollutants is therefore optimised by not using a settling unit.

We have used our steady-state analysis to investigate the relative effectiveness of the mechanisms by which micropollutants are removed from the reactor. We have shown that the condition for biodegradation to be more effective than adsorption is $k_{\text {biol }}^{*}>k_{\text {sor }}^{*}$. The values 
of these parameters for the micropollutants considered in this paper are provided in table 7 . From this we see that the condition $k_{\text {biol }}^{*}>k_{\text {sor }}^{*}$ never holds.

We conclude that even for the micropollutants described as being 'highly biodegradable with low sorption' that adsorption is a more effective removal mechanism than biodegradation.

\section{Acknowledgements}

Rubayyi would like express his deepest thank and gratitude and appreciation to King Abdulaziz City for Science and Technology for providing a research grant. He would like to extend his deepest thanks to the School of Mathematics and Applied Statistics at Wollongong University where the project was carried out. He would like to express his deepest thanks to Dr. Mark Nelson for his help, guidance and patience during this work. Both authors thank Dr. Eduardo Fernandez for his help in understanding experiments described in his research papers.

The authors thank the referees for their comments on our paper. In particular, we would like to thank 'Reviewer C' for: providing an exceptionally detailed reading of our paper, making many constructive comments on how our manuscript could be improved, suggesting that we include an overview of models for settling units and bringing a number of papers to our attention. 


\section{A Symbols used}

In the following we denote the units of $S$ and $X$ by $|S|$ and $|X|$, respectively. The scaled variables are listed at the end of the table.

AHTN Tonalide

ASM1 Activated sludge model number 1

ASP Activated sludge process

$\mathcal{C} \quad$ The recycle concentration factor. $(\mathcal{C}>1)$

$\mathcal{C}_{\max } \quad$ The maximum value of the concentration factor

$\mathcal{C}_{\max }=(R+1) /(R+w)$

$C_{g} \quad$ Gas-phase concentration of micropollutant. $\quad \mu \mathrm{g} \mathrm{L}^{-1}$

$C_{p} \quad$ The concentration of particulate micropollutants. $\quad \mu \mathrm{g} \mathrm{L}^{-1}$

$C_{p, \text { in }} \quad$ The concentration of particulate micropollutants in the feed. $\quad \mu \mathrm{g} \mathrm{L}^{-1}$

$C_{s} \quad$ The concentration of soluble micropollutants. $\quad \mu \mathrm{g} \mathrm{L}^{-1}$

$C_{s, \text { in }} \quad$ The concentration of soluble micropollutants in the feed. $\quad \mu \mathrm{g} \mathrm{L}^{-1}$

CBZ Carbamazepine

DCF Diclofenac

DZP Diazepam

ERY Erythromycin

F Flowrate through the bioreactor. $\quad \mathrm{L} \mathrm{day}^{-1}$

FLX Fluoxetine

$H \quad$ Henry coefficient of the micropollutant. $\quad(\mu \mathrm{g} \mathrm{L})_{\text {wastewater }} /(\mu \mathrm{g} \mathrm{L})_{\text {air }}$

HHCB Galaxolide

IBP Ibuprofen

$\begin{array}{lll}K_{d} & \text { Solid-liquid partitioning coefficient. } & \mathrm{L}(\mathrm{g} \mathrm{SS})^{-1}\end{array}$

$K_{L, A} \quad$ Mass transfer coefficient $\quad\left(\right.$ day $\left.^{-1}\right)$

$K_{S} \quad$ Monod constant for heterotrophic biomass. $\quad$ g COD L $^{-1}$

$K_{S C} \quad$ Micropollutant affinity constant. $\quad \mu \mathrm{g} \mathrm{L}^{-1}$

$M_{2} \quad$ Monod kinetics for readily biodegradable soluble substrate. _ -

NPX Naproxen

$Q_{\text {air }} \quad$ Aeration flowrate. $\quad L_{\text {air }}$ day $^{-1}$ 
$R \quad$ Recycle ratio based on volumetric flow rates.

ROX Roxithromycin

$S_{S} \quad$ Concentration of soluble substrate.

g $\mathrm{COD} \mathrm{L}^{-1}$

$S_{s, \text { in }} \quad$ Substrate concentration in the feed.

g $\mathrm{COD} \mathrm{L}^{-1}$

SMX Sulfamethoxazole

$T_{C} \quad$ Micropollutant transformation capacity.

$\mu \mathrm{g} /(\mathrm{g} \mathrm{COD})$

TMP Trimethoprim

TSS Total suspended solids

g SS L ${ }^{-1}$

$V \quad$ Volume of the bioreactor.

$\mathrm{L}$

$X_{B, H} \quad$ Concentration of particulate biomass (heterotrophs).

g $\mathrm{COD} \mathrm{L}^{-1}$

$X_{B, H \text {,in }}$ Concentration of particulate biomass (heterotrophs)

g $\mathrm{COD} \mathrm{L}^{-1}$ in the feed.

$X_{\text {TSS }} \quad$ Total suspended solids in the reactor.

g SS L ${ }^{-1}$

$Y_{H} \quad$ Heterotrophic yield factor.

$b_{H} \quad$ Heterotrophic decay coefficient.

$\left(\mathrm{g} \mathrm{COD} \mathrm{L}^{-1}\right) /\left(\mathrm{g} \mathrm{COD} \mathrm{L}^{-1}\right)$

$c_{2} \quad$ Conversion factor from COD to TSS for component $X_{B, H}$

day $^{-1}$

$k_{\text {biol }} \quad$ Biological degradation kinetic constant.

$(\mathrm{g} \mathrm{SS}) /(\mathrm{g} \mathrm{COD})$

$k_{\text {biol }}^{\prime} \quad$ Biological degradation kinetic constant under conditions of

$\mathrm{L}(\mathrm{g} \text { COD day })^{-1}$ constant biomass.

$k_{c} \quad$ The maximum rate of biodegradation of the micropollutant

$\left(\mu \mathrm{g}(\mathrm{g} \text { COD day })^{-1}\right)$ when there is no growth substrate

$k_{\text {des }} \quad$ Desorption kinetic constant.

day $^{-1}$

$k_{\text {sor }} \quad$ Sorption kinetic constant.

$\mathrm{L}(\mathrm{g} \text { SS day })^{-1}$

$r_{\text {biol }} \quad$ Biological removal rate.

$\mu \mathrm{g} \mathrm{L}^{-1} \mathrm{day}^{-1}$

$t \quad$ Time.

day

$w \quad$ The fraction of the recycle stream that is wasted.

$\mu \quad$ Specific growth rate model.

$\left(\right.$ day $\left.^{-1}\right)$

$\mu_{\max } \quad$ Maximum specific growth rate for biomass.

day $^{-1}$

$\tau \quad$ Residence time.

day. $\tau=V / F$ 
$C_{p}^{*} \quad$ Scaled concentration of particulate micropollutants

$$
C_{p}^{*}=C_{p} / C_{s, \text { in }}
$$

$C_{p, \text { in }}^{*} \quad$ The concentration of particulate micropollutants in the feed.

$C_{p, \text { in }}^{*}=C_{p, \text { in }} / C_{s, \text { in }}$

$C_{s}^{*} \quad$ Scaled concentration of soluble micropollutants

$C_{s}^{*}=C_{s} / C_{s, \text { in }}$

$K_{d}^{*} \quad$ The dimensionless solid-liquid partitioning coefficient

$K_{d}^{*}=c_{2} K_{d} Y_{H} K_{S}$

$Q_{\text {eff }} \quad$ The dimensionless effective aeration flowrate

$Q_{\mathrm{eff}}=H Q_{\mathrm{air}} / V \mu_{\max }$.

$R^{*} \quad$ Effective recycle parameter.

$R^{*}=\left(\mathcal{C}_{\max }-1\right) R$

$S^{*} \quad$ Scaled concentration of soluble substrate

$S^{*}=S_{S} / K_{S}$

$S_{s, \text { in }}^{*} \quad$ The dimensionless substrate substrate concentration in the feed.

$S_{s, \text { in }}^{*}=S_{s, \text { in }} / K_{S}$.

$X^{*} \quad$ Scaled concentration of particulate biomass

$X^{*}=X_{B, H} /\left(K_{S} Y_{H}\right)$

$X_{0}^{*} \quad$ Scaled concentration of particulate biomass in the feed

$X_{0}^{*}=X_{B, H, \text { in }} /\left(K_{S} Y_{H}\right)$

$b_{H}^{*} \quad$ The dimensionless heterotrophic decay coefficient.

$b_{H}^{*}=b_{H} / \mu_{\max }$.

$k_{\text {biol }}^{*} \quad$ The dimensionless biotransformation kinetic constant

$k_{\text {biol }}^{*}=k_{\text {biol }} Y_{H} K_{S} / \mu_{\max }$.

$k_{\text {sor }}^{*} \quad$ The dimensionless sorption kinetic constant

$k_{\mathrm{sor}}^{*}=c_{2} K_{\mathrm{sor}} Y_{H} K_{S} / \mu_{\max }$.

$t^{*} \quad$ Scaled time

$t^{*}=\mu_{\max , H} \cdot t$

$\tau^{*} \quad$ Dimensionless residence time.

$\tau^{*}=V \mu_{\max } / F$ 
$\tau_{\mathrm{cr}}^{*} \quad$ Value of the scaled residence time at the transcritical bifurcation-

$$
\tau_{\mathrm{cr}}^{*}=\left(1+S_{s, \text { in }}^{*}\right)\left(1-R^{*}\right) /\left[S_{s, \text { in }}^{*}-\left(1+S_{s, \text { in }}^{*}\right) b_{\mathrm{H}}^{*}\right]
$$




\section{References}

[1] F.I. Hai, L.D. Nghiem, S.J. Khan, W.E. Price, and K. Yamamoto. Wastewater reuse: Removal of emerging trace organic contaminants. In F.I. Hai, K. Yamamoto, and C. Lee, editors, Membrane Biological Reactors: Theory, Modeling, Design, Management and Applications to Wastewater Reuse, pages 165-205. IWA, London, United Kingdom, 2014.

[2] Y. Luo, W. Guo, H.H. Ngo, L.D. Nghiem, F.I. Hai, J. Zhang, S. Liang, and X.C. Wang. A review on the occurrence of micropollutants in the aquatic environment and their fate and removal during wastewater treatment. Science of The Total Environment, 473-474:619641, 2014. doi:10.1016/j.scitotenv.2013.12.065.

[3] M. Pomiès, J.-M. Choubert, C. Wisniewski, and M. Coquery. Modelling of micropollutant removal in biological wastewater treatments: A review. Science of The Total Environment, 443:733-748, 2013. DOI:10.1016/j.scitotenv.2012.11.037.

[4] C. Abegglen, A. Joss, C.S. McArdell, G. Fink, M.P. Schlüsener, T.A. Ternes, and H. Siegrist. The fate of selected micropollutants in a single-house MBR. Water Research, 43:2036-2046, 2009. DOI : 10.1016/j.watres.2009.02.005.

[5] L. Delgadillo-Mirquez, L. Lardon, J-P. Steyer, and D. Patureau. A new dynamic model for bioavailability and cometabolism of micropollutants during anaerobic digestion. Water Research, 45:4511-4521, 2011. DOI:10.1016/j.watres.2011.05.047.

[6] E. Fernandez-Fontaina, I. Pinho, M. Carballa, F. Omil, and J.M. Lema. Biodegradation kinetic constants and sorption coefficients of micropollutants in membrane bioreactors. Biodegradation, 24:165-177, 2013. DOI :10.1007/s10532-012-9568-3.

[7] E. Fernandez-Fontaina, M. Carballa, F. Omil, and J.M. Lema. Modelling cometabolic biotransformation of organic micropollutants in nitrifying reactors. Water Research, 65:371383, 2014. DOI:10.1016/j . watres.2014.07.048.

[8] B.N. Jacobsen and E. Arvin. Biodegradation kinetics and fate modelling of pentachlorophenol in bioaugmented activated sludge reactors. Water Research, 30:1184-1194, 1996. DOI : 10.1016/0043-1354(95) 00259-6. 
[9] A. Joss, S. Zabczynski, A. Göbel, B. Hoffmann, D. Löffler, C.S. McArdell, T.A. Ternes, A. Thomsen, and H. Siegrist. Biological degradation of pharmaceuticals in municipal wastewater treatment: Proposing a classification scheme. Water Research, 40:1686-1696, 2006. https://doi.org/10.1016/j.watres.2006.02.014.

[10] H. Melcer, J.P. Bell, D.J. Thompson, C.M. Yendt, J. Kemp, and P. Steel. Modeling volatile organic contaminants fate in wastewater treatment plants. Journal of Environmental Engineering, 120:588-609, 1994. DOI=10.1061/(ASCE) 0733-9372(1994) 120:3(588).

[11] W.J. Parker, H.D. Monteith, J.P. Bell, H. Melcer, and P. Mac Berthouex. Comprehensive fate model for metals in municipal wastewater treatment. Journal of Environmental Engineering, 120:1266-1283, 1994. DOI : 10.1061/(ASCE) 0733-9372(1994) 120:5(1266).

[12] H. Siegrist, A. Alder, W. Gujer, and W. Giger. Behavior and modeling of NTA degradation in activated-sludge systems. Water Science and Technology, 21:315-324, 1989. http: //wst.iwaponline.com/content/21/4-5/315.

[13] T. Urase and T. Kikuta. Separate estimation of adsorption and degradation of pharmaceutical substances and estrogens in the activated sludge process. Water Research, 39:1289-1300, 2005. DOI:10.1016/j.watres.2005.01.015.

[14] C.S. Criddle. The kinetics of cometabolism. Biotechnology and Bioengineering, 41:10481056, 1993. DOI :10.1002/bit. 260411107.

[15] M. Henze, C.P.L. Grady Jr, W. Gujer, G.V.R. Marais, and T. Matsuo. A general model for single-sludge wastewater treatment systems. Water Research, 21:505-515, 1987. doi: $10.1016 / 0043-1354(87) 90058-3$.

[16] G. Byrns. The fate of xenobiotic organic compounds in wastewater treatment plants. Water Research, 35:2523-2533, 2001. DOI : 10 .1016/S0043-1354(00) 00529-7.

[17] C.E. Cowan, R.J. Larson, T.C.J. Feijtel, and R.A. Rapaport. An improved model for predicting the date of consumer product chemicals in wastewater treatment plants. Water Research, 27:561-573, 1993. DOI : 10.1016/0043-1354(93)90165-E. 
[18] E. Fernandez-Fontaina, F. Omil, J.M. Lema, and M. Carballa. Influence of nitrifying conditions on the biodegradation and sorption of emerging micropollutants. Water Research, 46:5434-5444, 2012. doi:10.1016/j.watres.2012.07.037.

[19] J. Struijs, Stoltenkamp, and D. van de Meent. A spreadsheet-based box model to predict the fate of xenobiotics in a municipal wastewater treatment plant. Water Research, 25:891900, 1991. DOI : 10 . 1016/0043-1354(91)90170-U.

[20] S. Suarez, J.M. Lema, and F. Omil. Removal of pharmaceutical and personal care products (PPCPs) under nitrifying and denitrifying conditions. Water Research, 44:3214-3224, 2010. doi:10.1016/j.watres.2010.02.040.

[21] J. Wang, C.P. Huang, H.E. Allen, I. Poesponegoro, H. Poesponegoro, and L.R. Takiyama. Effects of dissolved organic matter and $\mathrm{pH}$ on heavy metal uptake by sludge particulates exemplified by copper (II) and nickel (II): Three-variable model. Water Environmental Research, 71(2):139-147, 1999. www.jstor.org/stable/25045190.

[22] S-H. Yoon and S. Lee. Critical operational parameters for zero sludge production in biological wastewater treatment processes combined with sludge disintegration. Water Research, 39(15):3738 - 3754, 2005. DOI:10.1016/j.watres.2005.06.015.

[23] U. Jeppsson and S. Diehl. On the modelling of the dynamic propagation of biological components in the secondary clarifier. Water Science and Technology, 34(5-6):85-92, 1996. doi : 10.1016/0273-1223(96)00632-4.

[24] D. Orhon, F.G. Babuna, and O. Karahan. Industrial Wastewater Treatment by Activated Sludge. IWA Publishing, London, first edition, 2009.

[25] G.A. Ekama, G.I. Bernard, F.W. Gunthert, P. Krebs J.A. McCorquodale, D.S. Parker, and E.J. Wahlberg. Secondary Settling Tanks: Theory, Modelling, Design and Operation. IWA Publishing, London, UK, 1997.

[26] S. Diehl, J. Zambrano, and B. Carlsson. Steady-state analyses of activated sludge processes with plug-flow reactor. Journal of Environmental Chemical Engineering, 5(1):795-809, 2017. doi:10.1016/j.jece.2016.06.038. 
[27] G. Xu, F. Yin, Y. Xu, and H-Q. Yu. A force-based mechanistic model for describing activated sludge settling process. Water Research, 127:118-126, 2017. 10.1016/j . watres . 2017.10 .013

[28] I. Takács and G.A. Ekama. Final settling. In M. Henze, M.C.M. van Loosdrecht, G.A. Ekama, and D. Brdjanovic, editors, Biological Wastewater Treatment, chapter 12, pages 309-334. IWA Publishing, 2008.

[29] B. Li and M.K. Stenstrom. Research advances and challenges in one-dimensional modeling of secondary settling tanks - A critical review. Water Research, 65:40-63, 2014. doi: $10.1016 / j$. watres.2014.07.007.

[30] E. Torfs, M.C. Martí, F. Locatelli, S. Balemans, R. Bürger, S. Diehl, J. Laurent, P.A. Vanrolleghem, P. François, and I. Nopens. Concentration-driven models revisited: towards a unified framework to model settling tanks in water resource recovery facilities. Water Science and Technology, 75(3):539-551, 2017. doi:10.2166/wst.2016.485.

[31] C. Cadet, V.D.S. Martins, and D. Dochain. Dynamic modeling of clarifier-thickeners for the control of wastewater treatment plants: a critical analysis. In 2015 19th International Conference on System Theory, Control and Computing (ICSTCC), pages 571-576, 2015. doi:10.1109/ICSTCC.2015.7321354.

[32] A.M. Karpinska and J. Bridgeman. CFD-aided modelling of activated sludge systems - A critical review. Water Research, 88:861-879, 2016. doi:10.1016/j.watres.2015.11.008.

[33] I. Takács, G.G. Patry, and D. Nolasco. A dynamic model of the clarification-thickening process. Water Research, 25(10):1263-1271, 1991. doi :10.1016/0043-1354(91)90066-Y.

[34] U. Jeppsson and S. Diehl. An evaluation of a dynamic model of the secondary clarifier. Water Science and Technology, 34(5-6):19-26, 1996. wst.iwaponline.com/content/34/ $5-6 / 19$.

[35] R.W. Watts, S.A. Svoronos, and B. Koopman. One-dimensional modeling of secondary clarifiers using a concentration and feed velocity-dependent dispersion coefficient. Water Research, 30(9):2112-2124, 1996. DOI : 10.1016/0043-1354(96)00024-3. 
[36] B. Li and M.K. Stenstrom. A sensitivity and model reduction analysis of one-dimensional secondary settling tank models under wet-weather flow and sludge bulking conditions. Chemical Engineering Journal, 288:813-823, 2016. doi:10.1016/j.cej.2015.12.055.

[37] E. Torfs, T. Maere, R. Bürger, S. Diehl, and I. Nopens. Impact on sludge inventory and control strategies using the benchmark simulation model no. 1 with the bürger-diehl settler model. Water Science and Technology, 71(10):1524-1535, 2015. doi:10.2166/wst. 2015. 122.

[38] B. Li and M.K. Stenstrom. Practical identifiability and uncertainty analysis of the onedimensional hindered-compression continuous settling model. Water Research, 90:235-246, 2016. doi:10.1016/j. watres.2015.12.034.

[39] J. Alex, L. Benedetti, J. Copp, K.V. Gernaey, U. Jeppsson, I. Nopens, M.-N. Pons, L. Rieger, C. Rosen, J.P. Steyer, P. Vanrolleghem, and S. Winkler. Benchmark simulation model no. 1 (BSM1). CODEN:LUTEDX/(TEIE-7229) 80-2186, Dept. of Industrial Electrical Engineering and Automation Lund University, 1998. http://www.iea.1th.se/ publications/Reports/LTH-IEA-7229.pdf.

[40] S. Diehl, J. Zambrano, and B. Carlsson. Steady-state analysis of activated sludge processes with a settler model including sludge compression. Water Research, 88:104-116, 2016. DOI : 10.1016/j.watres. 2015.09.052.

[41] R. Bürger, J. Careaga, S. Diehl, C. Mejías, I. Nopens, E. Torfs, and P.A. Vanrolleghem. Simulations of reactive settling of activated sludge with a reduced biokinetic model. Computers $\&$ Chemical Engineering, 92:216-229, 2016. doi:10.1016/j.compchemeng.2016. 04.037.

[42] E. Ramin, X. Flores-Alsina, G. Sin, K.V. Gernaey, U. Jeppsson, P.S. Mikkelsen, and B.G. Plósz. Influence of selecting secondary settling tank sub-models on the calibration of WWTP models - A global sensitivity analysis using BSM2. Chemical Engineering Journal, 241:28 - 34, 2014. doi:10.1016/j.cej.2013.12.015. 
[43] M.I. Nelson, J.L. Quigley, and X.D. Chen. A fundamental analysis of continuous flow bioreactor and membrane bioreactor models with non-competitive product inhibition. AsiaPacific Journal of Chemical Engineering, 4(1):107-117, 2009. DOI:10.1002/apj. 234. 